\title{
Experimental Study on Desorption Characteristics of Coalbed Methane under Variable Loading and Temperature in Deep and High Geothermal Mine
}

\author{
Haifeng Ma $\mathbb{D},{ }^{1,2}$ Lingjie Wang $\mathbb{D}^{2},{ }^{2}$ Housheng Jia $\mathbb{D}^{3},{ }^{3}$ Jucai Chang, ${ }^{2}$ YingMing $L i \mathbb{D},{ }^{2}$ \\ Xiangyang Zhang, ${ }^{2,3}$ Zuxiang $\mathrm{Hu}^{2}$ and Zhiqiang Yin ${ }^{2}{ }^{2}$ \\ ${ }^{1}$ State Key Laboratory of Mining Response and Disaster Prevention and Control in Deep Coal Mines, \\ Anhui University of Science and Technology, Huainan, Anhui 232001, China \\ ${ }^{2}$ Faculty of Energy and Safety Engineering, Anhui University of Science and Technology, Huainan, Anhui 232001, China \\ ${ }^{3}$ Key Laboratory of Safety and High-Efficiency Coal Mining, Ministry of Education, Anhui University of Science and Technology, \\ Huainan, Anhui 232001, China \\ Correspondence should be addressed to Lingjie Wang; 2509356841@qq.com and Housheng Jia; jiahousheng@hpu.edu.cn
}

Received 12 August 2020; Revised 25 September 2020; Accepted 27 October 2020; Published 27 November 2020

Academic Editor: Richeng Liu

Copyright $\odot 2020$ Haifeng Ma et al. This is an open access article distributed under the Creative Commons Attribution License, which permits unrestricted use, distribution, and reproduction in any medium, provided the original work is properly cited.

\begin{abstract}
Due to the influence of deep high stress, geothermal heat, and other factors, the law of desorption of methane in coal seams is more complicated in the process of mining deep coal seams, which is prone to methane over-limit, coal and gas outburst, and other accidents. In order to study the desorption characteristics of coalbed methane under different loading and temperature conditions, the desorption tests at different deformation stages of coal containing methane were carried out in the process of loadingadsorption-desorption-reloading until the coal sample was destroyed by using the seepage-adsorption-desorption test system on coal and rock mass, and the test programs were different combinations of gas pressure 1.2 $\mathrm{MPa}$, two kinds of confining pressure, and three kinds of temperature. The results show that the cumulative methane desorption amount corresponding to each deformation stage presents a convex parabolic increase trend with the increase in desorption time, while the desorption rate presents a power function decay trend. Under the condition of the same desorption time, the cumulative methane desorption amount from large to small is residual deformation stage, compaction stage, near the peak stress, plastic deformation stage, and elastic deformation stage. Under the same confining pressure, temperature, and methane pressure, the maximum desorption rate from large to small is residual deformation stage, near the peak stress, plastic deformation stage, compaction stage, and elastic deformation stage. The desorption and diffusion of methane are promoted under the higher temperature and lower confining pressure, which presents a certain mechanism of promoting desorption. The thermal movement of methane molecules is intensified with the increase in temperature, and the adsorption effect between methane molecules and the molecules at the surface of the coal is weakened. The cumulative methane desorption amount and the maximum desorption rate increase with the increase in temperature. The cumulative methane desorption in the residual deformation stage is obviously greater than that in other deformation stages. The increase in confining pressure inhibits the development and expansion of pore fractures in raw coal specimen and hinders the increase in the effective desorption surface area. The cumulative methane desorption amount and the maximum desorption rate decrease with the increase in confining pressure.
\end{abstract}

\section{Introduction}

Coal seam is a typical dual medium. There are a lot of pores and microcracks in coal matrix. Coalbed methane (the main component is methane) is an unconventional natural gas concentrated in the micropores of coal seam [1]. The process of coalbed methane production includes two stages of desorption and migration [2]. Coal seams are generally in the environment where stress, temperature, gas, and other factors work together. The adsorption and desorption 
characteristic of methane is affected by temperature, stress, gas, pore structure and metamorphism of coal, and other factors. For a specific coal seam, the stress state, temperature, and gas in the coal seam will change during the mining process. When the gas pressure in the coal seam reaches the critical desorption pressure, the adsorbed gas will start desorption and change from the adsorption state to the free state. Especially in the process of high-intensity mining deep coal seams, the influence of stress and temperature change on methane adsorption and desorption is more complex, which is easy to induce methane over-limit, coal and gas outburst, and other accidents. Therefore, the law of methane desorption in the process of mining coal seam should be studied, which has a certain guiding significance for preventing the occurrence of methane over-limit, coal and gas outburst, and other disasters; at the same time, it provides a certain basis for improving the methane extraction rate.

Scholars at home and abroad have studied gas desorption characteristics mainly from the aspects of coal structure, pore pressure, temperature, and acoustic field. Methane adsorption and desorption behaviors on moist shales were studied and elucidated [3], and the moisture adsorption on four shales selected from the Lower Silurian Longmaxi Formation located in southern Sichuan Basin of China was investigated. The question of how $\mathrm{CO}_{2}$ played a role in affecting the adsorption/desorption of $\mathrm{CH}_{4}$ was investigated using the low-field nuclear magnetic resonance technique [4]. Hu et al. [5] studied the law of methane desorption in coal under the action of microwave field with or without controlled source and discussed the mechanism of influence of microwave field of controlled source on methane desorption characteristics. An adsorption-desorption experimental device was developed and used to study the energy variation rules in the process of gas adsorption and desorption in coal [6]. The processes of methane $\left(\mathrm{CH}_{4}\right)$ and carbon dioxide $\left(\mathrm{CO}_{2}\right)$ adsorption and desorption were reviewed, as well as the displacement of $\mathrm{CH}_{4}$ by $\mathrm{CO}_{2}$, at the molecular level, and the adsorption and desorption behavior of $\mathrm{CH}_{4}$ and $\mathrm{CO}_{2}$ was examined [7]. The laws of natural desorption of carbon monoxide during the crushing of coal simulating natural rock mass pressure were studied [8]. Low-pressure sorption tests were carried out on samples of selected Polish bituminous coal in coal-methane and coalcarbon dioxide systems, and the purpose was to determine the relationship between the petrographic composition of low-rank coal and the amount of gas stored in its porous structure and desorbed from it [9]. The fractal characteristics of several shale samples drilled at a depth of $2650 \mathrm{~m}$ were analyzed using scanning electron microscopy and image analysis, and the adsorption and desorption properties of supercritical shale gas were researched [10]. Isothermal methane desorption and diffusion experiments were conducted using the self-developed gas desorption and diffusion experimental system, and the pore structure of coal samples was analyzed [11]. Li et al. [12] established a dynamic evolution model of the gas diffusion coefficient of the loaded coal and used the single-hole model and the double-hole model to calculate the gas diffusion coefficient of coal samples with different particle sizes under the axial pressure of $0 \sim 12 \mathrm{MPa}$. The contact angle measurement and isothermal adsorption/desorption experiment of raw coal and samples treated with surfactants were conducted to investigate the wetting properties and methane adsorption/desorption characteristics [13]. Sampling of methane-bearing coal seams by freezing was proposed, and the coalbed gas desorption characteristics under freezing temperature were studied to verify the feasibility of this method [14]. Calibration, isothermal desorption, pressure step-down desorption, and pore dynamic experiments were conducted with high-rank coal samples using low-field nuclear magnetic resonance technology [15]. Wang et al. [16] obtained the effect of water on diffusion dynamics during methane desorption. Based on the experimental and molecular simulation results, Liu et al. [17] introduced the principle of heat and deformation effects from the micro and macro levels and studied the thermal deformation effects of coal in the process of carbon dioxide adsorption and desorption. Zhou et al. [18] revealed the mechanism of residual deformation accumulation of methane adsorption/desorption in coal mesostructures through the coal cyclic adsorption and desorption methane test. Characterization of pore morphology and the effect of injected water on gas desorption characteristic were carried out using pore structure analyzers (N-2 adsorption and mercury intrusion methods), high-resolution scanning electron microscopy, and a homemade instrument (water-injecting desorption test) [19]. Four shale samples from the Lower Silurian Longmaxi Formation and the Lower Cambrian Shuijingtuo Formation in the eastern part of Chongqing, SW China, were subjected to canister desorption experiments at the reservoir and elevated temperatures (up to $90^{\circ} \mathrm{C}$ ) to investigate shale gas desorption behaviors and their variations in chemical and isotopic compositions of desorbed gases [20]. The coal temperature and gas pressure were measured by temperature and pressure sensors in the process of methane desorption, and the heat transfer model was established, and the temperature evolution during methane desorption in coal under different conditions (initial temperature and gas pressure) was simulated [21]. The experiments based on the self-built coal oxidation heating system in different gaseous environments and the high-temperature and high-pressure gas adsorption instrument were carried out, and the effect of methane on free radicals and surface functional groups at the optimum oxidation temperature was studied by using the electron spin resonance spectrum and Fourier transform infrared spectroscopy [22]. The combination of methane desorption experiments and molecular simulations was adopted to investigate the effects of moisture on the methane desorption characteristics of the Zhaozhuang coal, and the microscopic mechanism was analyzed [23]. A technique for accelerating coalbed methane desorption to increase extraction efficiency using microwaves was presented, and methane desorption experiments with and without real-time microwave loading were carried out in the laboratory [24]. The mathematical expression of K-1 was established by the self-developed high/low temperature pressure swing adsorption-desorption experimental system based on the diffusion theory and the physical meaning of fixed-size coal samples [25]. Bai et al. 
[26] carried out laboratory experiments on field hydraulic fracturing and gas adsorption-desorption and clarified the space-time effect of hydraulic fracturing on gas desorption and its mechanism. The gas desorption characteristics of coal under different adsorption pressures and particle sizes were affected by the high pressure water and superheated steam [27]. The influence characteristics of the maximum pressure on the path of $\mathrm{CO}_{2}$ isothermal desorption line were studied by Wang et al. [28]. The thermogravimetric method was used to obtain the excess adsorption/desorption of $\mathrm{CH}_{4}$ and $\mathrm{C}_{2} \mathrm{H}_{6}$ on two typical shale samples, and simplified local density theory/Peng-Robinson equation of the state model was then applied to calculate the adsorbed density of $\mathrm{CH}_{4}$ and $\mathrm{C}_{2} \mathrm{H}_{6}$ on both shale samples, which was then applied to convert the measured excess adsorption into absolute adsorption values [29]. The desorption and diffusion characteristics of coal samples mixed with different particle sizes over time were studied under constant temperature and pressure, and the results show that coal samples with different particle sizes affected the desorption and diffusion of gas, which had a positive impact on methane recovery [30]. The results of studies on sorption and $\mathrm{CO}_{2}$ desorptions from coals from two Polish mines that differed in petrographic and structural properties were presented, and the kinetics of $\mathrm{CO}_{2}$ desorption from plane sheet samples were compared with the kinetics of sample shrinkage [31]. The mechanical properties and permeability evolution during the failure of weakly anisotropic rock were examined, and the influences of bedding angle and osmotic pressure are examined [32]. Duan et al. [33] studied the effect of pressure-relief on coal fields during gas drainage and mining, and the permeability, acoustic emission, and energy dissipation properties of coal under tiered cyclic unloading were experimentally investigated. According to the isothermal adsorption and desorption experiments of Wufeng-Longmaxi Formations in Jiaoshiba block of the Fuling shale gas field in Sichuan basin, China, 7 core samples from isothermal adsorption experiment and 30 core samples from desorption experiment were analyzed [34]. Competitive adsorption, substitution desorption, and the capillary effect were analyzed to study the effect of the critical moisture content and liquid water on methane adsorption and desorption, and the effects of the fluid pressure, fracturing fluid, fracturing time, pore pressure, and other variables on methane adsorption and desorption characteristics were researched [35].

Coal seam is generally in an environment where factors such as stress, temperature, and gas work together. Mining activities will have an impact on the stress, gas occurrence state, and temperature environment of coal seam. If the above factors lead to the increase in gas desorption and diffusion speed, a large amount of gas will flood into the working face, which will not only cause gas exceeding the limit but also increase the risk of coal and gas outburst or even gas explosion. At present, there are few studies on the desorption characteristics of gas in the process of mining of coal seams. So, the desorption characteristics of gas under the comprehensive stress-temperature-gas action are studied by changing the stress environment of coal in a certain gas and temperature environment. This research results will have an important guiding significance for the prevention and control of dynamic disasters, such as efficient gas extraction and coal and gas outburst.

\section{Overview of Coal Mine}

Dingji coal mine is located in Fengtai County, Huainan City, Anhui Province, as shown in Figures 1 and 2. It is about 45 kilometers away from the urban area with convenient transportation. The mine field is 14.75 kilometers long from east to west and 11 kilometers wide from north to south. There are 9 coal seams in the mine, and the occurrence of coal seam is stable. The geological reserves of the mine field are 1279 million tons, and the recoverable reserves are 640 million tons. The design production capacity of the mine is 5 million tons/year.

The temperature measurement results of the geological exploration show that the Dingji coal mine is a secondary heat damage zone. The ground temperature of $-500 \mathrm{~m}$ varies from $20^{\circ} \mathrm{C}$ to $35.5^{\circ} \mathrm{C}$. The ground temperature increases with the increase in depth, and the rock temperature at the bottom of the hole is above $40^{\circ} \mathrm{C}$. The geothermal gradient of the whole mine field is $2.3 \sim 4.1^{\circ} \mathrm{C} / \mathrm{hm}$, with an average of $3.2^{\circ} \mathrm{C} / \mathrm{hm}$, which belongs to the anomaly geothermal area. The geothermal data of some boreholes are shown in Table 1. With the increase in the mining depth, the geothermal temperature is constantly rising. Meanwhile, there are many large machines and equipment underground, which emit large amounts of heat. High-temperature operation seriously affects the physical and mental health of the miners and the mining progress.

\section{Methodology}

3.1. Specimen Preparation. The coal samples used in this test are taken from 1231 (1) working face of 11-2 coal seam in Huainan Dingji coal mine. The average thickness of 11-2 coal seam is $2.45 \mathrm{~m}$, and the average dip angle is $4^{\circ}$. The coal seam is a simple and stable coal seam with the original methane pressure of 1.2 MPa. The coal gathering from 1231 (1) working face is sent to the laboratory, the raw coal pillars with a diameter of $50 \mathrm{~mm}$ are made from the gathering coal by using core-drilling machine, and then the raw coal pillars are cut and polished by using the high-speed cutting machine, and the standard specimens with a size of $\Phi 50 \mathrm{~mm} \times 100 \mathrm{~mm}$ are used, as shown in Figure 3. The prepared raw coal specimens are placed in an oven for drying (drying temperature: $110^{\circ} \mathrm{C}$ and duration: $10 \mathrm{~h}$ ) and stored in a drying oven after cooling to room temperature for testing.

The geothermal temperature range of 1231 (1) working face is $40^{\circ} \mathrm{C} \sim 50^{\circ} \mathrm{C}$, the test temperature is set as $30^{\circ} \mathrm{C}, 45^{\circ} \mathrm{C}$, and $60^{\circ} \mathrm{C}$, respectively, so the coal samples can be placed in a relatively real temperature environment during the test, and the coal samples can reflect the mechanical characteristics that are more in line with the actual situation on the site. 


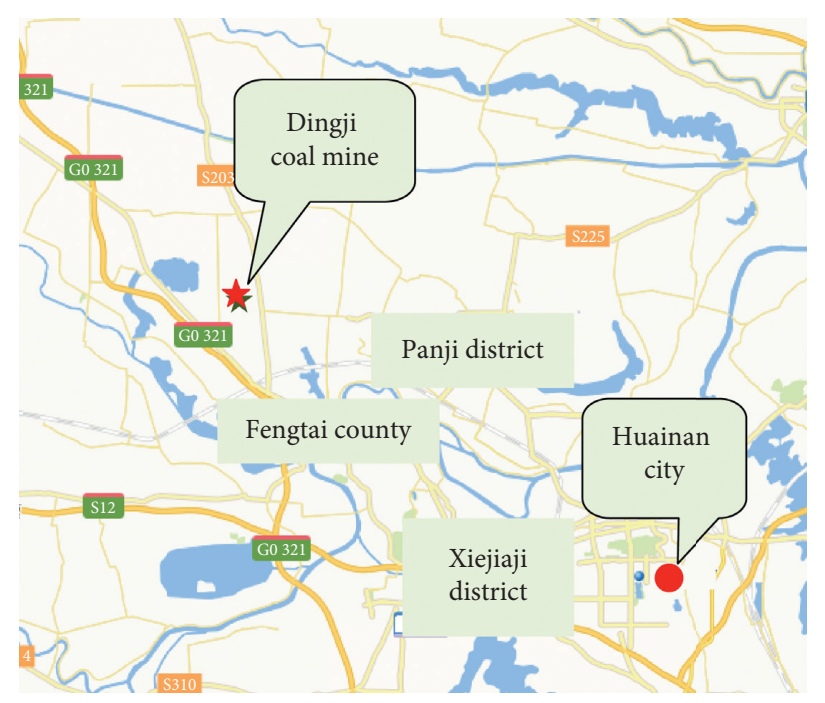

Figure 1: Location map of Dingji coal mine.

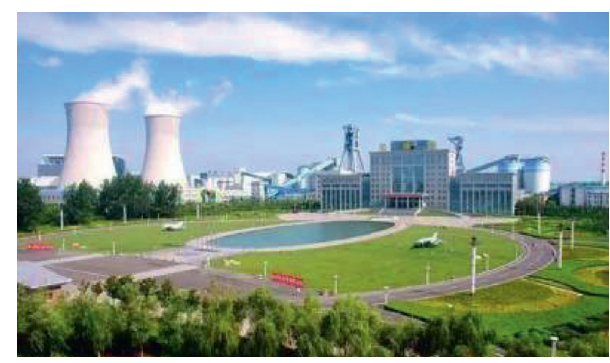

FIGURE 2: Industrial square of Dingii coal mine.

TABLE 1: Geothermal data of partial boreholes.

\begin{tabular}{lccc}
\hline $\begin{array}{l}\text { Hole } \\
\text { number }\end{array}$ & $\begin{array}{c}\text { Hole } \\
\text { depth }(\mathrm{m})\end{array}$ & $\begin{array}{c}\text { Rock temperature at the } \\
\text { bottom of the hole }\left({ }^{\circ} \mathrm{C}\right)\end{array}$ & $\begin{array}{c}\text { Geothermal } \\
\text { gradient } \\
\left({ }^{\circ} \mathrm{C} \cdot \mathrm{hm}^{-1}\right)\end{array}$ \\
\hline $16-4$ & 874.3 & 44.9 & 3.7 \\
$17-6$ & 884.34 & 49.5 & 4.1 \\
$20-4$ & 910.45 & 50.2 & 3.8 \\
847 & 906.46 & 51.8 & 4 \\
$23-6$ & 975.28 & 52.7 & 3.6 \\
\hline
\end{tabular}

3.2. Test System. The seepage-adsorption-desorption test system on coal and rock mass (Figure 4) mainly includes host machine, servo loading system (Figure 5), triaxial pressure chamber, adsorption-desorption system (Figure 6), temperature control system, gas pressure control system (multiple leak detection and alarm, with high safety), data acquisition system, and safety protection system. The test system can meet the requirements of the adsorption and desorption test of various gases, which could be used to carry out experimental research on mechanical characteristics, seepage, adsorption, and desorption of coal and rock under different loads and different temperatures.

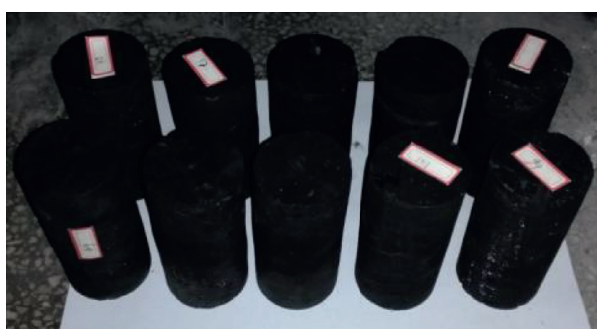

Figure 3: Raw coal specimen prepared.

\subsection{Test Plan and Process}

3.3.1. Test Plan. In order to obtain desorption characteristics of coal containing methane under different loadings and temperatures, the desorption test schemes at different axial compression under two kinds of confining pressure (3 MPa and $5 \mathrm{MPa})$, three kinds of temperature $\left(30^{\circ} \mathrm{C}, 45^{\circ} \mathrm{C}\right.$, and $60^{\circ} \mathrm{C}$ ), and methane pressure of $1.2 \mathrm{MPa}$ (the original methane pressure in coal seam) are designed, and the characteristics of methane desorption under the condition of different combination experiment are studied. In order to obtain the difference between desorption characteristics of coal containing methane under different loading and temperature conditions and conventional isothermal desorption characteristics, conventional isothermal desorption tests under no loading condition are carried out at the same time.

3.3.2. Test Process. Methane, the purity is $99.99 \%$, is used in the experiment instead of coalbed methane. Taking the temperature of $30^{\circ} \mathrm{C}$, the confining pressure of $3 \mathrm{MPa}$, and the methane pressure of $1.2 \mathrm{MPa}$ as an example, the specific test steps are as follows:

(1) Initial loading: take a dried specimen, wrap the specimen in a heat-shrinkable tube, and load it into a triaxial pressure chamber. Load the axial pressure and 


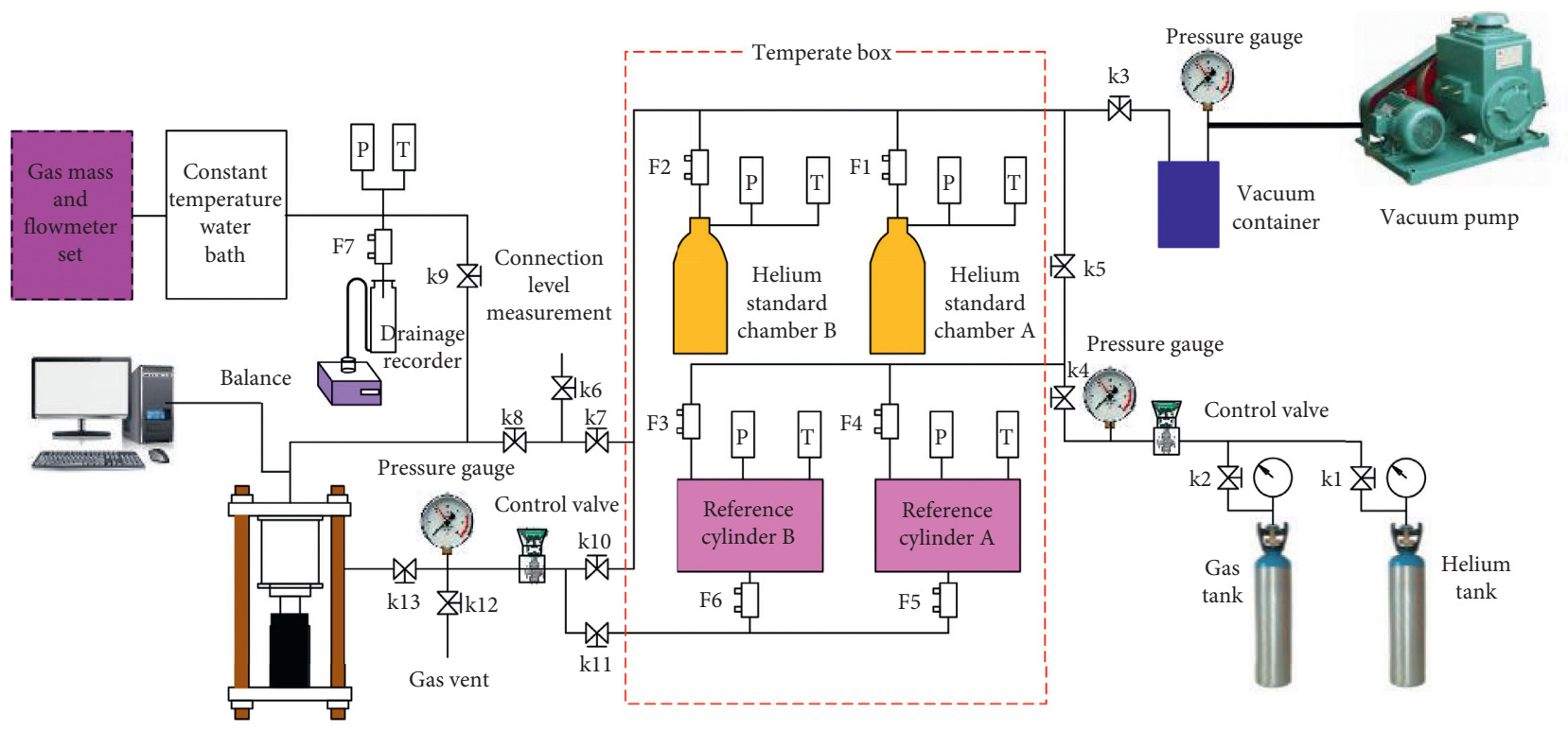

Three-axis pressure system

FiguRE 4: Test system. 1-drainage recorder; 2-balance; 3 -three-axis pressure system; 4-control valve; 5-vacuum container; 6-vacuum container; 7 -pressure gauge; 8 -control valve; 9-gas tank; 10 -helium tank.

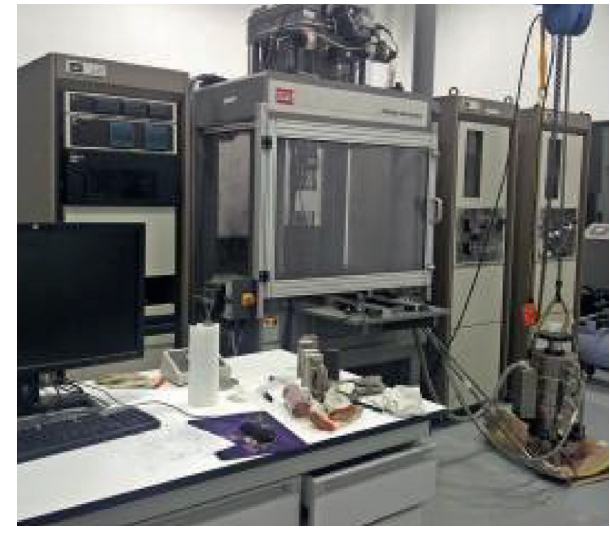

FIGURE 5: Servo loading system.

confining pressure to $3 \mathrm{MPa}$ slowly with stress control mode according to the proportion of hydrostatic pressure.

(2) Vacuum pumping: check the air tightness of the test system, vacuum pump the system for $12 \mathrm{~h}$ until the vacuum reaches the required value (less than $20 \mathrm{~Pa}$ ), and calibrate the dead volume (free space) with helium.

(3) Adsorption test: set the system temperature to $30^{\circ} \mathrm{C}$ through the temperature control system, open the methane cylinder valve, regulating valve, and reference cylinder valve, fill the system with methane, and adjust the reference cylinder pressure value to preset methane pressure. After reaching the predetermined methane pressure, start the adsorption program for methane adsorption, and the data acquisition system will automatically collect the adsorption data, with the adsorption equilibrium time not less than $12 \mathrm{~h}$.

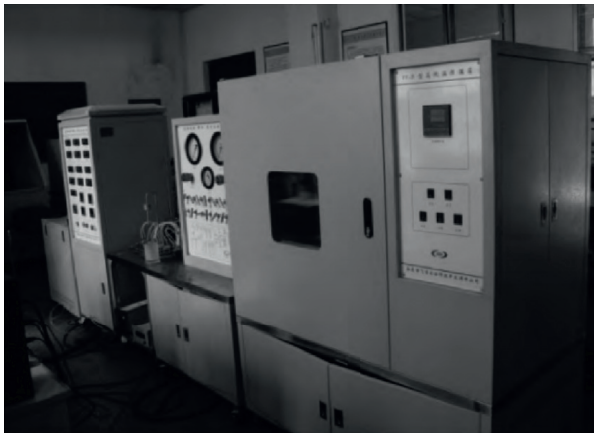

FIgURe 6: Adsorption-desorption system.

(4) Desorption test: after the adsorption balance, close the methane cylinder valve, regulating valve, and reference cylinder valve, open the outlet valve, start the desorption program for methane desorption, and the data collection system will automatically collect the desorption data.

(5) After the adsorption and desorption test under one axial pressure, increase the axial pressure and start the adsorption and desorption test of the next axial pressure. Repeat the steps (2) (4) until the coal sample is destroyed.

\section{Result Analysis and Discussion}

4.1. Stress and Strain Characteristics of Coal Containing Methane. In order to determine the deformation stage of coal in the process of loading and deformation, the raw coal specimens were first subjected to the mechanical test when the confining pressure was $3 \mathrm{MPa}$ and $5 \mathrm{MPa}$ and the 
methane pressure was 1.2 MPa, respectively. Three tests were conducted under each confining pressure condition, as shown in Table 2. The stress-strain curves of the specimens were similar, and the stress-strain curve of specimen S-3-2 is shown in Figure 7. According to the stress-strain curve of coal specimen, the deformation of coal specimen can be divided into compaction stage, elastic deformation stage, plastic deformation stage, and residual deformation stage.

The test results show that when the confining pressure is $3 \mathrm{MPa}$ and the methane pressure is $1.2 \mathrm{MPa}$, the average stress boundary point of the raw coal specimen in the compaction stage and elastic deformation stage is $12.8 \mathrm{MPa}$, the average stress boundary point in the elastic deformation stage and plastic deformation stage is $29.4 \mathrm{MPa}$, and the average peak stress is $42.1 \mathrm{MPa}$. When the confining pressure was $5 \mathrm{MPa}$ and the methane pressure was $1.2 \mathrm{MPa}$, the average stress boundary point of raw coal specimens in the compaction stage and elastic deformation stage was 17.7 $\mathrm{MPa}$, the average stress boundary point in the elastic deformation stage and plastic deformation stage was 34.6 $\mathrm{MPa}$, and the average peak stress was $55.2 \mathrm{MPa}$.

According to the stress-strain curve characteristics of raw coal specimens at confining pressures of $3 \mathrm{MPa}$ and $5 \mathrm{MPa}$ and the methane pressure of $1.2 \mathrm{MPa}$, when the confining pressures of $3 \mathrm{MPa}$ are designed, the axial compression is $6.5 \mathrm{MPa}$ in the compaction stage, $23.4 \mathrm{MPa}$ in the elastic deformation stage, $35.8 \mathrm{MPa}$ in the plastic deformation stage, $40.5 \mathrm{MPa}$ in near the peak stress, and $25.8 \mathrm{MPa}$ in the residual deformation stage. When the confining pressures of $5 \mathrm{MPa}$ are designed, the axial compression is $6.5 \mathrm{MPa}$ in the compaction stage, $23.4 \mathrm{MPa}$ in the elastic deformation stage, $41.6 \mathrm{MPa}$ in the plastic deformation stage, $51.6 \mathrm{MPa}$ in near the peak stress, and $25.8 \mathrm{MPa}$ in the residual deformation stage, as shown in Table 3.

4.2. Desorption Characteristics without Loading. In order to obtain the difference between desorption characteristics of coal containing methane coal and conventional isothermal desorption characteristics under different loadings and temperatures, desorption tests were carried out under normal isothermal conditions $\left(30^{\circ} \mathrm{C}, 45^{\circ} \mathrm{C}\right.$, and $\left.60^{\circ} \mathrm{C}\right)$ and the methane pressure of $1.2 \mathrm{MPa}$ without loading. The results are shown in Figure 8.

It can be seen from Figure 8 that the methane desorption amount and desorption time of raw coal specimens under constant temperature without loading show a convex parabola relationship. At different temperatures, the methane desorption amount has the same evolution rule; that is, with the increase in desorption time, the desorption amount shows a change characteristic of gradually increasing and tending to be stable. At the same desorption time (60 minutes), the maximum desorption of raw coal at $30^{\circ} \mathrm{C}$, $45^{\circ} \mathrm{C}$, and $60^{\circ} \mathrm{C}$ is $93 \mathrm{ml}, 101 \mathrm{ml}$, and $116 \mathrm{ml}$, respectively. Under the same temperature difference, the increase range of maximum desorption varies to some extent. The increase in temperature from $45^{\circ} \mathrm{C}$ to $60^{\circ} \mathrm{C}$ is 1.875 times that of temperature from $30^{\circ} \mathrm{C}$ to $45^{\circ} \mathrm{C}$, and raw coal specimens show great desorption characteristics at higher temperatures.

The relationship between methane desorption rate and desorption time is power function under constant temperature without loading. At different temperatures, the methane desorption rate has the same evolution rule. With the increase in desorption time, the desorption rate shows the change characteristic of "rapid attenuation at first and then tending to be stable," and the desorption rate attenuates obviously at the initial stage of desorption. When the temperature is $30^{\circ} \mathrm{C}, 45^{\circ} \mathrm{C}$, and $60^{\circ} \mathrm{C}$, the corresponding maximum desorption rate is $19.8 \mathrm{ml} / \mathrm{min}, 24.5 \mathrm{ml} / \mathrm{min}$, and $37 \mathrm{ml} / \mathrm{min}$, respectively. Under the condition of the same temperature difference, the attenuation amplitude of the maximum desorption rate has a certain difference. The attenuation amplitude of temperature increasing from $45^{\circ} \mathrm{C}$ to $60^{\circ} \mathrm{C}$ is 2.66 times that of temperature increasing from $30^{\circ} \mathrm{C}$ to $45^{\circ} \mathrm{C}$, and raw coal specimens show a larger desorption rate characteristics at higher temperature. The desorption capacity of raw coal specimens increases with the increase in temperature and shows strong desorption characteristics at higher temperature.

4.3. Evolution Characteristics of Desorption Amount under Variable Loading and Temperature. In the process of gradual loading, raw coal specimens successively go through compaction stage, elastic deformation stage, plastic deformation stage, and residual deformation stage. The desorption amount of different deformation stages varies with time, as shown in Figures 9 and 10.

(1) It can be seen from Figure 9 that (1) the methane desorption law of raw coal specimen at different deformation stages is consistent with the no-loading condition. The cumulative desorption increases in a convex parabolic shape with the increase in desorption time. In the compaction stage, elastic deformation stage, plastic deformation stage, and near the peak stress, the accumulated methane desorption amount of raw coal specimens has little difference, but in the residual deformation stage, the accumulated methane desorption amount increases obviously.

(2) Under the conditions of the confining pressure of $3 \mathrm{MPa}$, the methane pressure of $1.2 \mathrm{MPa}$, and the temperature of $30^{\circ} \mathrm{C}$, the cumulative desorption amount in 60 minutes corresponding to the compaction stage, elastic deformation stage, plastic deformation stage, near the peak stress, and residual deformation stage is $101 \mathrm{ml}, 70 \mathrm{ml}, 82 \mathrm{ml}, 91 \mathrm{ml}$, and $252 \mathrm{ml}$, respectively. When the temperature increased to $45^{\circ} \mathrm{C}$, the cumulative desorption in 60 minutes corresponding to the compaction stage, elastic deformation stage, plastic deformation stage, near the peak stress, and residual deformation stage is $109 \mathrm{ml}, 75 \mathrm{ml}, 87 \mathrm{ml}, 99 \mathrm{ml}$, and $280 \mathrm{ml}$, respectively. When the temperature increased to $60^{\circ} \mathrm{C}$, the cumulative desorption in 60 minutes corresponding 
TABLE 2: Mechanical test results.

\begin{tabular}{|c|c|c|c|c|}
\hline Confining pressure & $\begin{array}{l}\text { Specimen } \\
\text { number }\end{array}$ & $\begin{array}{l}\text { Stress at the boundary point of } \\
\text { compaction-elastic deformation } \\
\text { stage (MPa) }\end{array}$ & $\begin{array}{l}\text { Stress at the boundary point of the } \\
\text { elastic-plastic deformation stage }(\mathrm{MPa})\end{array}$ & $\begin{array}{c}\text { Peak } \\
\text { stress }(\mathrm{MPa})\end{array}$ \\
\hline \multirow{3}{*}{$3 \mathrm{MPa}$} & S-3-1 & 11.9 & 28.9 & 44.1 \\
\hline & $S-3-2$ & 12.7 & 29.8 & 40.8 \\
\hline & $S-3-3$ & 13.8 & 29.5 & 41.4 \\
\hline \multirow[t]{2}{*}{ Average } & & 12.8 & 29.4 & 42.1 \\
\hline & S-5-1 & 16.7 & 33.6 & 57.2 \\
\hline \multirow[t]{2}{*}{$5 \mathrm{MPa}$} & S-5-2 & 18.9 & 36.4 & 53.6 \\
\hline & $S-5-3$ & 17.5 & 33.8 & 54.8 \\
\hline Average & & 17.7 & 34.6 & 55.2 \\
\hline
\end{tabular}

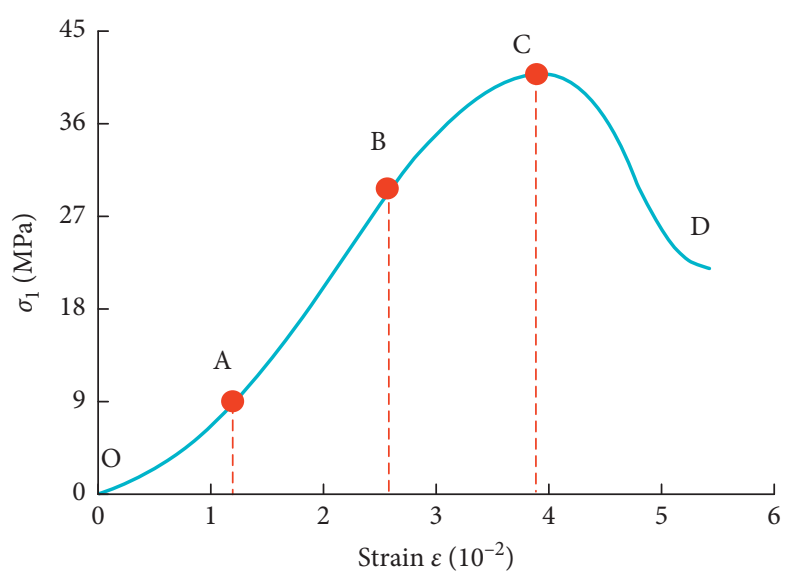

FiguRE 7: Stress-strain curve (specimen S-3-2). OA: compaction stage; AB: elastic deformation stage; BC: plastic deformation stage; CD: residual deformation stage.

TABle 3: Axial compression design at different deformation stages.

\begin{tabular}{|c|c|c|}
\hline Confining pressure $(\mathrm{MPa})$ & Different deformation stages & Axial compression (MPa) \\
\hline \multirow{5}{*}{3} & Compaction stage & 6.5 \\
\hline & Elastic deformation stage & 23.4 \\
\hline & Plastic deformation stage & 35.8 \\
\hline & Near the peak stress & 40.5 \\
\hline & Residual deformation stage & 25.8 \\
\hline \multirow{5}{*}{5} & Compaction stage & 6.5 \\
\hline & Elastic deformation stage & 23.4 \\
\hline & Plastic deformation stage & 41.6 \\
\hline & Near the peak stress & 51.6 \\
\hline & Residual deformation stage & 25.8 \\
\hline
\end{tabular}

to the compaction stage, elastic deformation stage, plastic deformation stage, near the peak stress, and residual deformation stage is $129 \mathrm{ml}, 85 \mathrm{ml}, 100 \mathrm{ml}$, $116 \mathrm{ml}$, and $327 \mathrm{ml}$, respectively. At temperatures of $30^{\circ} \mathrm{C}, 45^{\circ} \mathrm{C}$, and $60^{\circ} \mathrm{C}$, the accumulated desorption amount corresponding to different deformation stages in 60 minutes is in descending order: residual deformation stage, compaction stage, near the peak stress, plastic deformation stage, and elastic deformation stage.

(3) Under the conditions of the confining pressure of $3 \mathrm{MPa}$ and the methane pressure of $1.2 \mathrm{MPa}$, when the temperature increases from $30^{\circ} \mathrm{C}$ to $45^{\circ} \mathrm{C}$, the cumulative desorption in 60 minutes corresponding to the compaction stage, elastic deformation stage, plastic deformation stage, near the peak stress, and residual deformation stage increases by $8 \mathrm{ml}, 5 \mathrm{ml}$, $5 \mathrm{ml}, 8 \mathrm{ml}$, and $28 \mathrm{ml}$, respectively. When the temperature increases from $45^{\circ} \mathrm{C}$ to $60^{\circ} \mathrm{C}$, the cumulative desorption in 60 minutes corresponding to the compaction stage, elastic deformation stage, plastic deformation stage, near the peak stress, and residual deformation stage increases by $20 \mathrm{ml}, 10 \mathrm{ml}, 13 \mathrm{ml}$, $17 \mathrm{ml}$, and $47 \mathrm{ml}$, respectively. At the same 


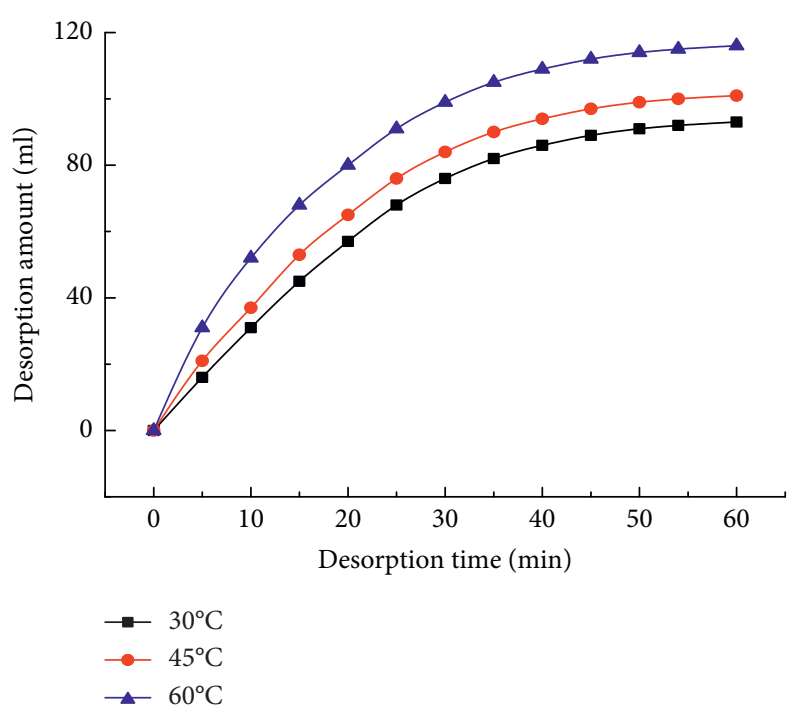

(a)

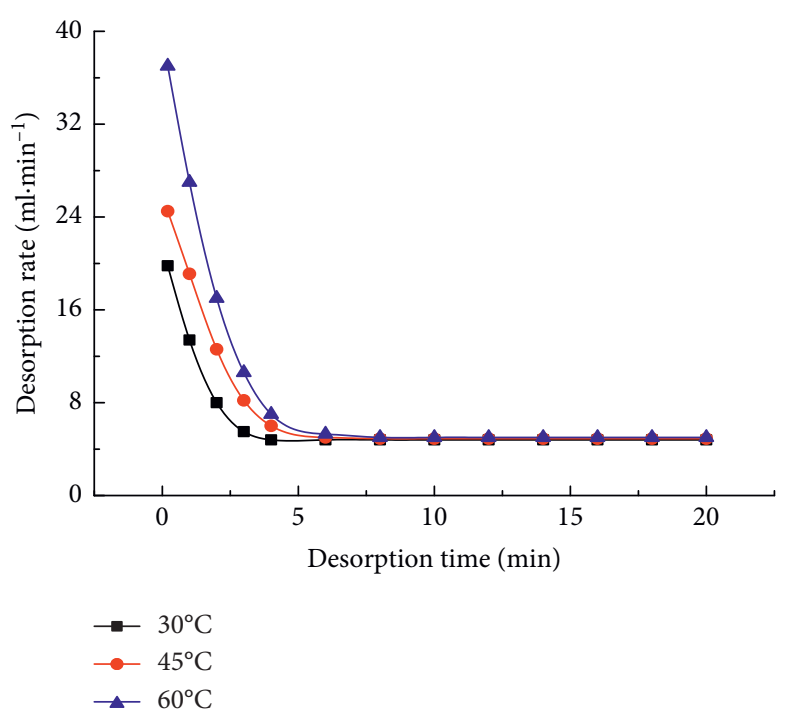

(b)

Figure 8: Desorption curve. (a) Desorption amount. (b) Desorption rate.

temperature difference, the increase in desorption amount at different deformation stages at higher temperature is greater than that at lower temperature, and the increase in temperature promoted the desorption of methane.

Figure 10 shows that (1) under the same condition of methane pressure and temperature, the methane desorption law of raw coal specimens at different deformation stages with the confining pressure of $5 \mathrm{MPa}$ is consistent with that at the confining pressure of $3 \mathrm{MPa}$. The desorption amount increases in a convex parabolic shape with the increase in desorption time. In the compaction stage, elastic deformation stage, plastic deformation stage, and near the peak stress, the corresponding cumulative gas desorption amount difference is small, but the accumulated methane desorption amount increases obviously in the residual deformation stage.

(2) Under the conditions of the confining pressure of $5 \mathrm{MPa}$, the methane pressure of $1.2 \mathrm{MPa}$, and the temperature of $30^{\circ} \mathrm{C}$, the accumulated desorption amount of raw coal specimens in 60 minutes corresponding to the compaction stage, elastic deformation stage, plastic deformation stage, near the peak stress, and residual deformation stage is $92 \mathrm{ml}$, $58 \mathrm{ml}, 71 \mathrm{ml}, 83 \mathrm{ml}$, and $205 \mathrm{ml}$, respectively. When the temperature increased to $45^{\circ} \mathrm{C}$, the cumulative desorption in 60 minutes corresponding to the compaction stage, elastic deformation stage, plastic deformation stage, near the peak stress, and residual deformation stage is $101 \mathrm{ml}, 69 \mathrm{ml}, 81 \mathrm{ml}, 92 \mathrm{ml}$, and $228 \mathrm{ml}$, respectively. When the temperature increased to $60^{\circ} \mathrm{C}$, the cumulative desorption in 60 minutes corresponding to the compaction stage, elastic deformation stage, plastic deformation stage, near the peak stress, and residual deformation stage is $111 \mathrm{ml}, 81 \mathrm{ml}, 92 \mathrm{ml}, 103 \mathrm{ml}$, and $270 \mathrm{ml}$, respectively. At the temperature of $30^{\circ} \mathrm{C}, 45^{\circ} \mathrm{C}$, and $60^{\circ} \mathrm{C}$, the cumulative desorption in 60 minutes corresponding to different deformation stages is in descending order: residual deformation stage, compaction stage, near the peak stress, plastic deformation stage, and elastic deformation stage.

(3) Under the conditions of the confining pressure of $5 \mathrm{MPa}$ and the methane pressure of $1.2 \mathrm{MPa}$, when the temperature was increased from $30^{\circ} \mathrm{C}$ to $45^{\circ} \mathrm{C}$, the increase amplitude of accumulated desorption in 60 minutes corresponding to compaction stage, elastic deformation stage, plastic deformation stage, near the peak stress, and residual deformation stage is $9 \mathrm{ml}, 11 \mathrm{ml}, 10 \mathrm{ml}, 9 \mathrm{ml}$, and $23 \mathrm{ml}$, respectively. When the temperature increased from $45^{\circ} \mathrm{C}$ to $60^{\circ} \mathrm{C}$, the cumulative desorption in 60 minutes corresponding to the compaction stage, elastic deformation stage, plastic deformation stage, near the peak stress, and residual deformation stage increased by $10 \mathrm{ml}, 12 \mathrm{ml}, 11 \mathrm{ml}, 11 \mathrm{ml}$, and $42 \mathrm{ml}$, respectively. At the same temperature difference, the increase in desorption amount at different deformation stages at higher temperature was greater than that at lower temperature, and the increase in temperature promoted the desorption of methane.

By analyzing the change rule of desorption amount of raw coal specimen at different deformation stages with desorption time, it can be seen that

(1) At the same desorption time, the cumulative methane desorption amount of raw coal specimen at each deformation stage has a basically consistent evolution rule; that is, the cumulative methane 


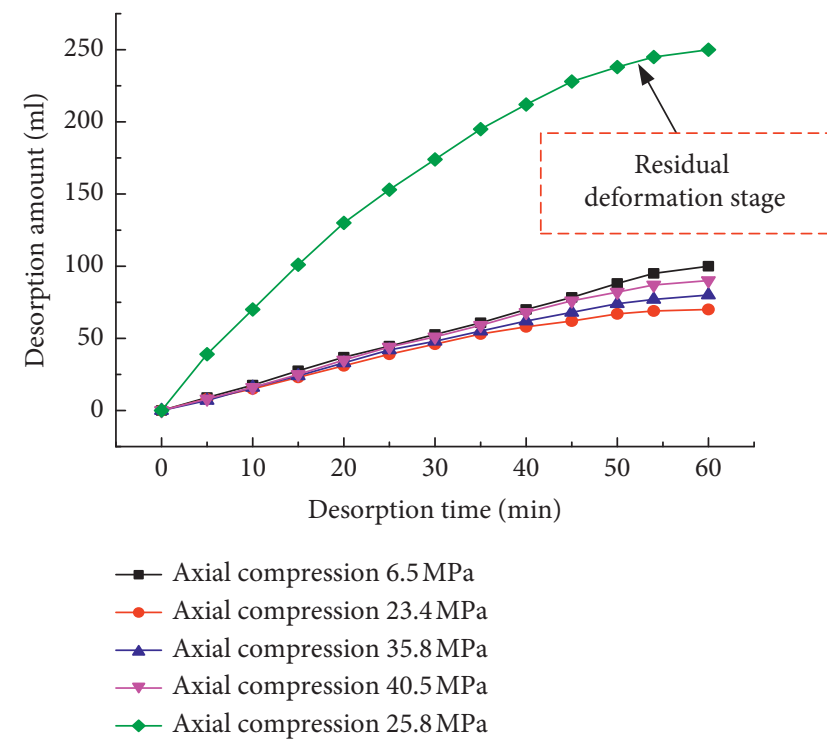

(a)

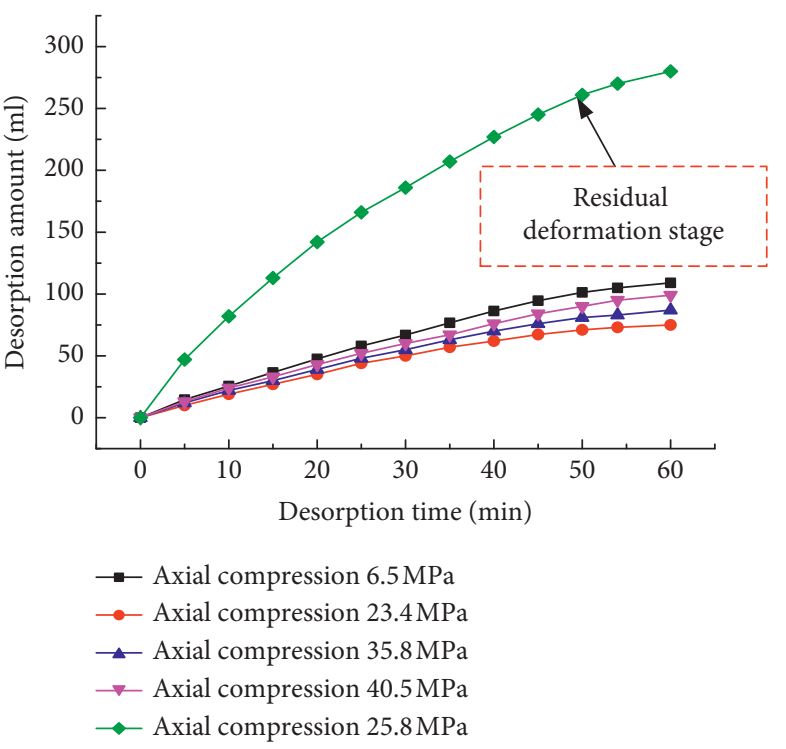

(b)

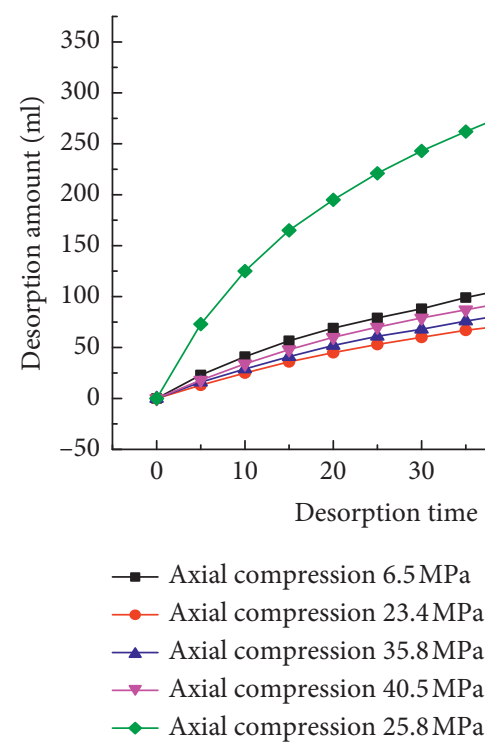

(c)

Figure 9: Desorption amount curve under the confining pressure of $3 \mathrm{MPa}$ at the temperature of (a) $30^{\circ} \mathrm{C}$, (b) $45^{\circ} \mathrm{C}$, and (c) $60^{\circ} \mathrm{C}$.

desorption amount shows a convex parabolic trend with the increase in desorption time. The difference of accumulated methane desorption corresponding to the compaction stage, elastic deformation stage, plastic deformation stage, and near the peak stress is small, but the accumulated methane desorption increased obviously in the residual deformation stage. The cumulative desorption in 60 minutes corresponding to different deformation stages is in descending order: residual deformation stage, compaction stage, near the peak stress, plastic deformation stage, and elastic deformation stage.

(2) Effects of temperature on desorption characteristics under the same confining pressure and methane pressure: under the same confining pressure and methane pressure, the accumulated desorption amount of raw coal specimens at different deformation stages in 60 minutes increases with the increase in temperature. The increase in temperature promotes the desorption of methane, and the higher the temperature is, the larger the desorption amount is.

(3) Effects of confining pressure on desorption characteristics under the same temperature and methane pressure: under the same temperature and methane pressure, the accumulated desorption amount of raw coal specimens at different deformation stages in 60 minutes decreases with the increase in confining pressure. The increase in confining pressure inhibits the desorption of methane. 


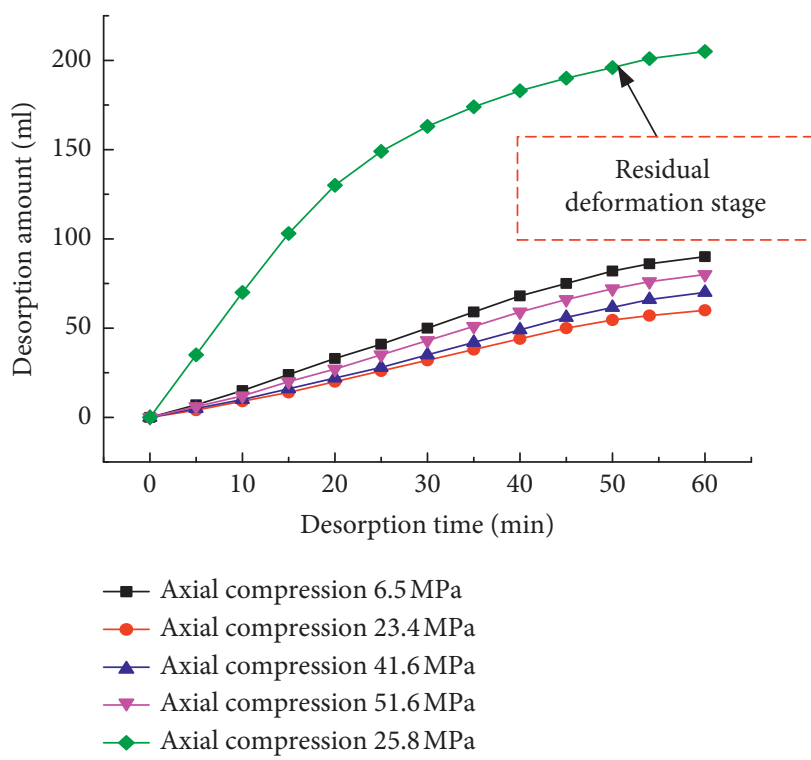

(a)

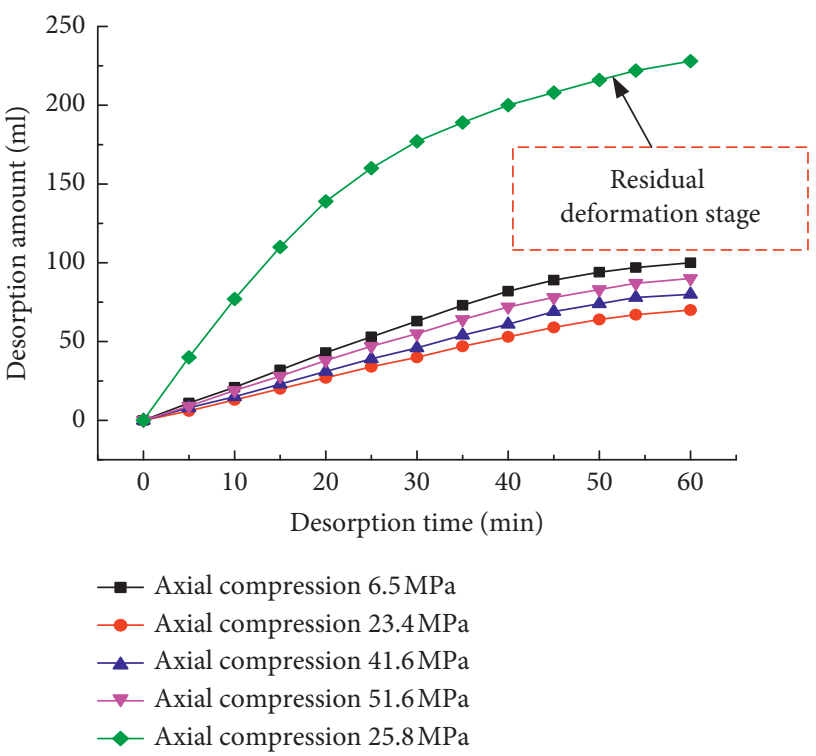

(b)

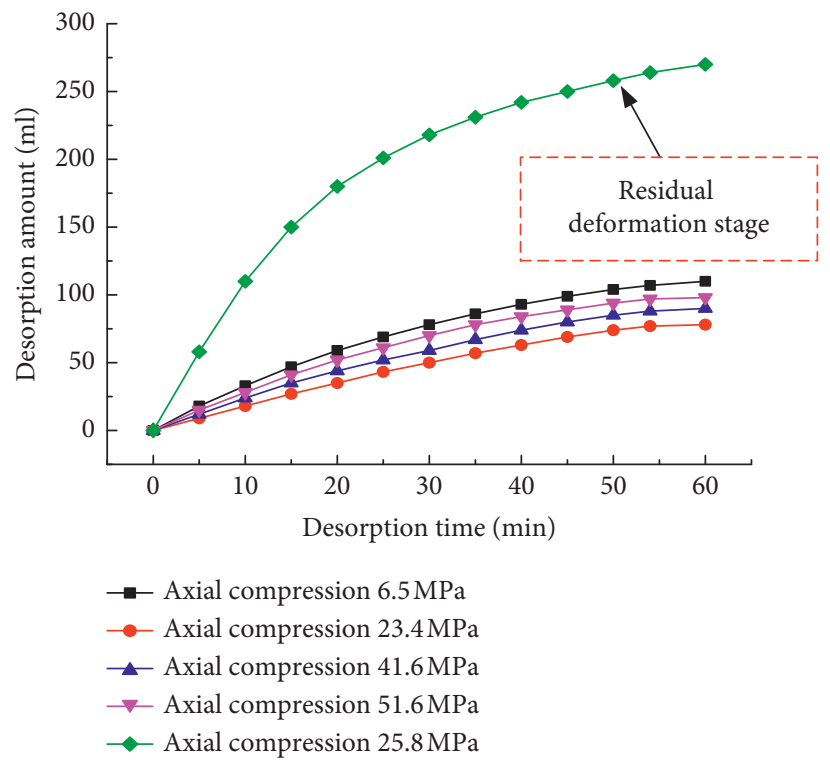

(c)

Figure 10: Desorption amount curve under the confining pressure of $5 \mathrm{MPa}$ at the temperature of (a) $30^{\circ} \mathrm{C}$, (b) $45^{\circ} \mathrm{C}$, and (c) $60^{\circ} \mathrm{C}$.

4.4. Evolution Law of the Maximum Desorption Amount in the Process of Stress and Strain. In the process of stress-strain on raw coal specimens, the relationship between the accumulated maximum desorption amount and the stress-strain within the same desorption time (60 minutes) is shown in Figure 11, and the relationship between the accumulated maximum desorption amount and the axial pressure is shown in Figure 12.

As can be seen from Figures 11 and 12, within the same desorption time (60 minutes), the cumulative maximum desorption amount presents a trend of "gradually decreasing firstly, then increasing, and then increasing obviously" with the increase in axial pressure. In the compaction deformation stage, the pore cracks in the raw coal specimen are compressed and closed with the increase in axial pressure, the effective desorption surface area of the raw coal specimen decreases, and the desorption amount decreases with the increase in axial pressure. In the elastic deformation stage, the pore fractures in the raw coal specimen are further compressed, the effective desorption surface area is further reduced, and the desorption amount continues to decrease with the increase in axial pressure and decreases to the minimum value at this stage. In the plastic deformation stage, the deformation of the raw coal specimen changes from elastic compression deformation to plastic deformation. Due to dilatancy effect, the closed pore fissure during compaction and elastic deformation stages is to become the effective desorption surface area again. The new microcracks are produced and interconnected in the coal specimen, and the fissured channel, which is conducive to methane 


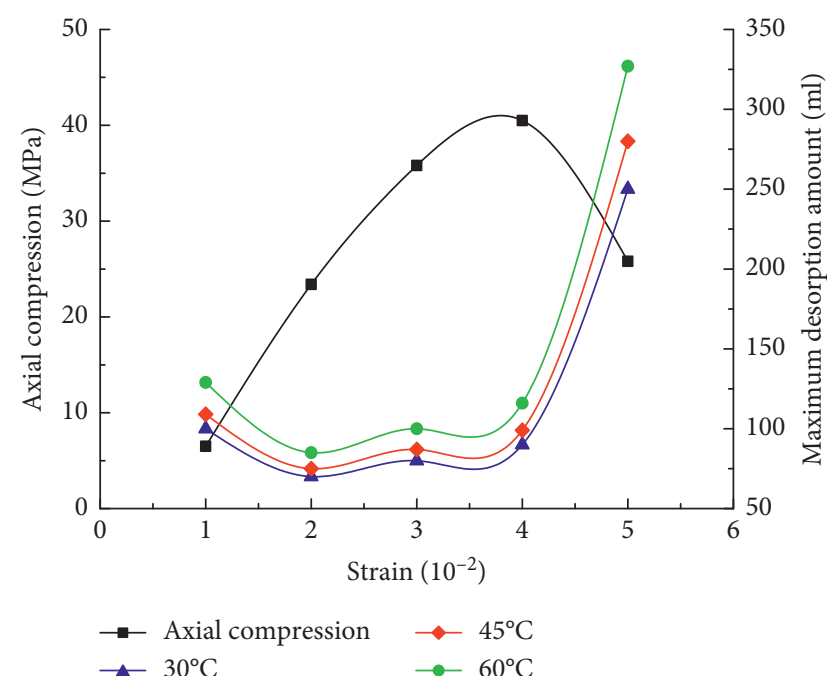

(a)

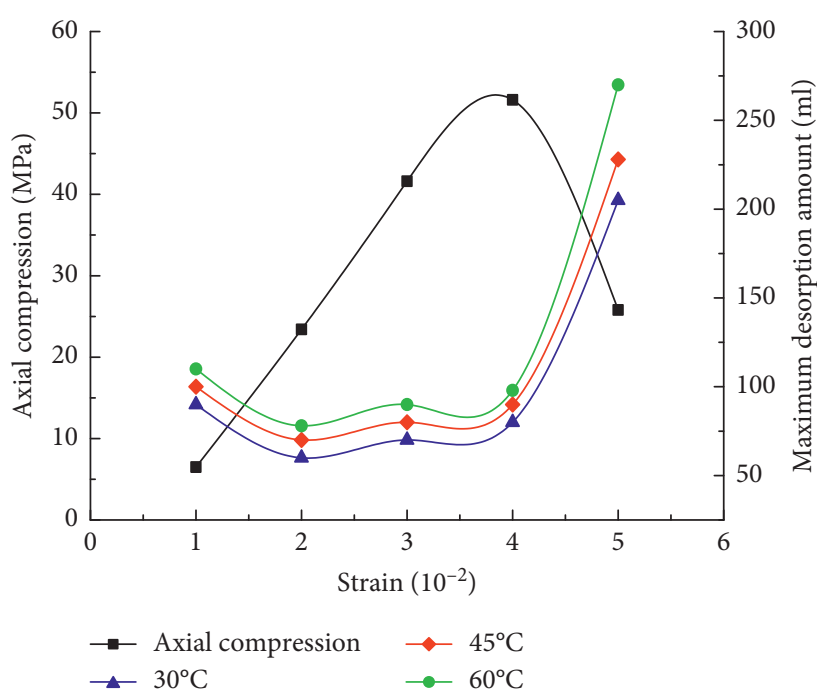

(b)

FIGURE 11: Relation curve between stress-strain and desorption amount under the confining pressure of (a) $3 \mathrm{MPa}$ and (b) $5 \mathrm{MPa}$.

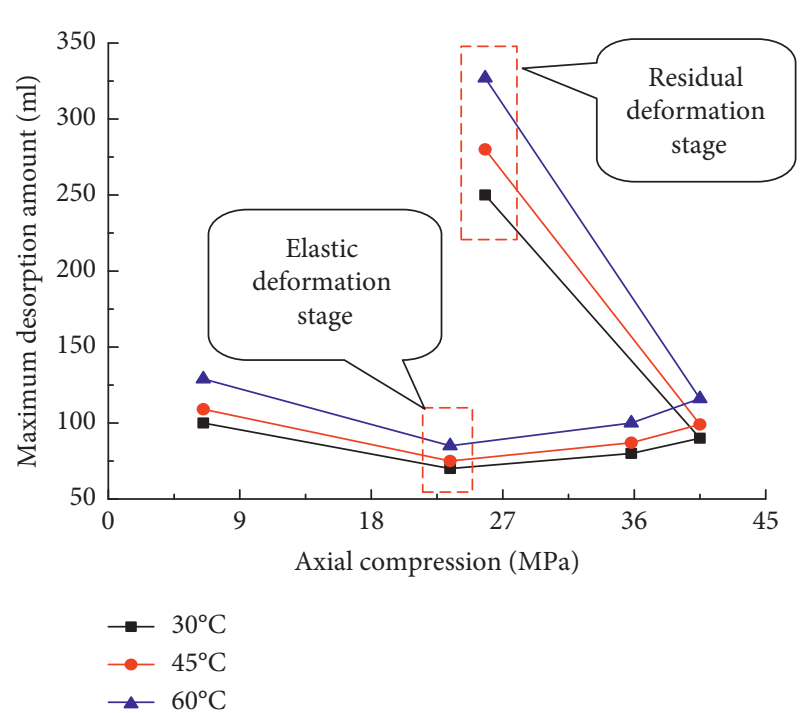

(a)

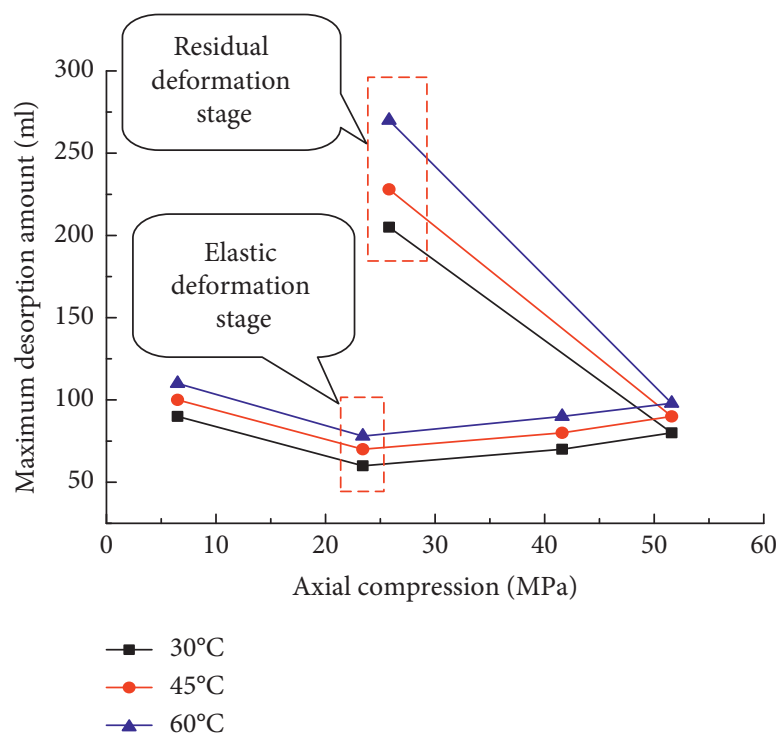

(b)

FIGURE 12: Relation curve between maximum desorption amount and axial pressure under the confining pressure of (a) $3 \mathrm{MPa}$ and (b) $5 \mathrm{MPa}$.

desorption, is formed. The effective desorption surface area is increased, the desorption of methane is promoted, and the methane desorption amount presents an increasing trend at the plastic deformation stage. Near the peak stress, more new cracks are appeared in the specimen and interlinked to form macrocracks with the increase in axial pressure. The relatively developmental fracture network is formed inside the specimen, the effective desorption surface area further increases, and the methane desorption amount of raw coal continues to increase near the peak value. In the residual deformation stage, the raw coal specimen is destroyed, more through cracks appear inside the specimen, the fracture network is more developed, and the channel that is conducive to methane desorption and the effective desorption surface area is expanded rapidly. The methane desorption amount of raw coal increases significantly at this stage, which is much higher than that at other deformation stages.

With the same confining pressure, the thermal motion of methane molecules is intensified due to the increase in temperature, which is beneficial to methane desorption. The accumulated methane desorption of raw coal specimen at the same deformation stage increases with the increase in temperature and reaches the maximum desorption at the residual deformation stage, and the accumulated methane 
desorption at this stage is obviously greater than that at other deformation stages. At the same temperature, due to the increase in confining pressure, the development and expansion of pore fractures in the raw coal specimen are inhibited, and also the increase in the effective desorption surface area is inhibited so that the corresponding accumulated methane desorption amount of the raw coal specimen at the same deformation stage decreases with the increase in confining pressure.

It can be seen from Figure 12 that the maximum accumulated desorption amount of raw coal specimens at the same desorption time (60 minutes) presents a trend of "gradually decreasing firstly, then increasing, and then increasing significantly" with the increase in axial pressure, and the accumulated methane desorption amount at the residual deformation stage is significantly greater than that at other deformation stages. This is because in the process of axial pressure increase, the original pore fractures in the raw coal specimen were closed and new fractures were generated and interlinked. The effective desorption area firstly decreased and then increased, leading to a decrease and then a gradual increase in methane desorption. After reaching the peak value, the raw coal specimen was destroyed, and a large number of pores and macroscopic fractures were generated in the specimen, forming a developed fracture network. The effective desorption surface area significantly increased, leading to the methane desorption amount significantly greater than that in other stages.

\subsection{Evolution Characteristics of Desorption Rate under} Variable Loading and Temperature. The change curve of desorption rate with time at different deformation stages of raw coal specimens is shown in Figures 13 and 14.

It can be seen from Figures 13 and 14 that the change law of methane desorption rate at different deformation stages of raw coal specimens is consistent without loading. The methane desorption rate shows a power function attenuation trend with the increase in desorption time, and the desorption rate goes through a rapid decay, slow decay, and tends to be stable.

Under the condition of the confining pressure of $3 \mathrm{MPa}$, the temperature of $30^{\circ} \mathrm{C}$, and the methane pressure of 1.2 $\mathrm{MPa}$, the maximum desorption rate corresponding to compaction stage, elastic deformation stage, plastic deformation stage, near the peak stress, and residual deformation stage is $18.6 \mathrm{ml} / \mathrm{min}, 15 \mathrm{ml} / \mathrm{min}, 23 \mathrm{ml} / \mathrm{min}, 27 \mathrm{ml} / \mathrm{min}$, and $39 \mathrm{ml} / \mathrm{min}$, respectively. Under the condition of the confining pressure of $3 \mathrm{MPa}$, the temperature of $45^{\circ} \mathrm{C}$, and the methane pressure of $1.2 \mathrm{MPa}$, the maximum desorption rate corresponding to compaction stage, elastic deformation stage, plastic deformation stage, near the peak stress, and residual deformation stage is $21 \mathrm{ml} / \mathrm{min}, 18 \mathrm{ml} / \mathrm{min}, 26 \mathrm{ml} /$ $\mathrm{min}, 30 \mathrm{ml} / \mathrm{min}$, and $44 \mathrm{ml} / \mathrm{min}$, respectively. Under the condition of the confining pressure of $3 \mathrm{MPa}$, the temperature of $60^{\circ} \mathrm{C}$, and the methane pressure of $1.2 \mathrm{MPa}$, the maximum desorption rate corresponding to compaction stage, elastic deformation stage, plastic deformation stage, near the peak stress, and residual deformation stage is
$31 \mathrm{ml} / \mathrm{min}, 25 \mathrm{ml} / \mathrm{min}, 41 \mathrm{ml} / \mathrm{min}, 49 \mathrm{ml} / \mathrm{min}$, and $63 \mathrm{ml} /$ min, respectively.

Under the condition of the confining pressure of $5 \mathrm{MPa}$, the temperature of $30^{\circ} \mathrm{C}$, and the methane pressure of 1.2 $\mathrm{MPa}$, the maximum desorption rate corresponding to compaction stage, elastic deformation stage, plastic deformation stage, near the peak stress, and residual deformation stage is $14 \mathrm{ml} / \mathrm{min}, 11 \mathrm{ml} / \mathrm{min}, 17 \mathrm{ml} / \mathrm{min}, 21 \mathrm{ml} / \mathrm{min}$, and $31 \mathrm{ml} / \mathrm{min}$, respectively. Under the condition of the confining pressure of $5 \mathrm{MPa}$, the temperature of $45^{\circ} \mathrm{C}$, and the methane pressure of $1.2 \mathrm{MPa}$, the maximum desorption rate corresponding to compaction stage, elastic deformation stage, plastic deformation stage, near the peak stress, and residual deformation stage is $18 \mathrm{ml} / \mathrm{min}, 14 \mathrm{ml} / \mathrm{min}, 21 \mathrm{ml} /$ $\mathrm{min}, 25 \mathrm{ml} / \mathrm{min}$, and $34 \mathrm{ml} / \mathrm{min}$, respectively. Under the condition of $5 \mathrm{MPa}$ confining pressure, $60^{\circ} \mathrm{C}$ temperature, and $1.2 \mathrm{MPa}$ methane pressure, the maximum desorption rate corresponding to compaction stage, elastic deformation stage, plastic deformation stage, near the peak stress, and residual deformation stage is $25 \mathrm{ml} / \mathrm{min}, 19.5 \mathrm{ml} / \mathrm{min}, 32 \mathrm{ml} /$ $\mathrm{min}, 40 \mathrm{ml} / \mathrm{min}$, and $49 \mathrm{ml} / \mathrm{min}$, respectively.

According to the above analysis, under the same confining pressure, temperature, and methane pressure, the maximum desorption rate corresponding to different deformation stages from large to small is residual deformation stage, near the peak stress, plastic deformation stage, compaction stage, and elastic deformation stage. Under the same confining pressure and methane pressure, with the increase in desorption temperature, the corresponding maximum desorption rate at different deformation stages increases. Under the same temperature and methane pressure, with the increase in confining pressure, the corresponding maximum desorption rate at different deformation stages decreased gradually.

4.6. Evolution Law of the Maximum Desorption Rate in the Process of Stress and Strain. In the process of stress-strain on raw coal specimens, the relationship between the maximum desorption rate corresponding to each deformation stage and the stress-strain is shown in Figure 15, and the relationship between the maximum desorption rate and axial pressure is shown in Figure 16.

It can be seen from Figures 15 and 16 that, in the process of stress and strain, the corresponding maximum desorption rate at different deformation stages presents a change trend of "gradually decreasing firstly, then increasing, and then increasing significantly." The reasons are analyzed as follows. In the compaction stage, the pore cracks in the raw coal specimen are continuously compressed with the increase in axial pressure, and the effective desorption surface area in the raw coal specimen decreases, which inhibits the desorption and diffusion movement of methane. In the elastic deformation stage, due to the increase in axial pressure, the pore fractures in the raw coal specimen are further compressed, and the effective desorption surface area is continuously reduced, further inhibiting the desorption and diffusion movement of methane. In the plastic deformation stage, the raw coal specimen occurred plastic deformation, 


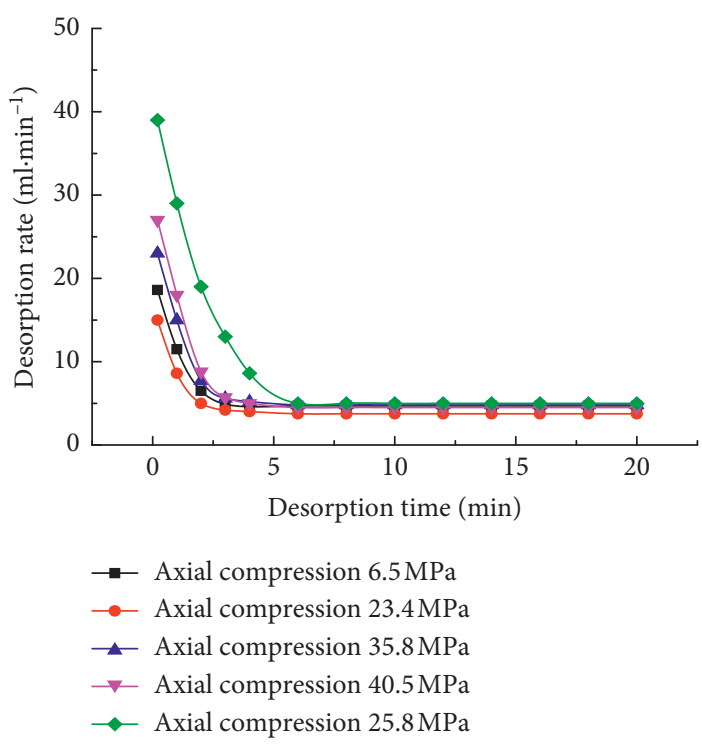

(a)

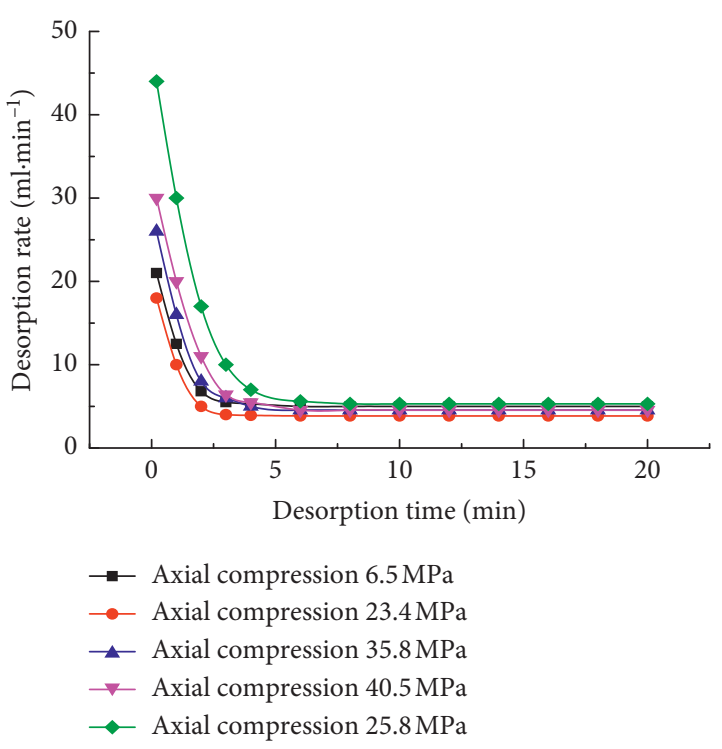

(b)

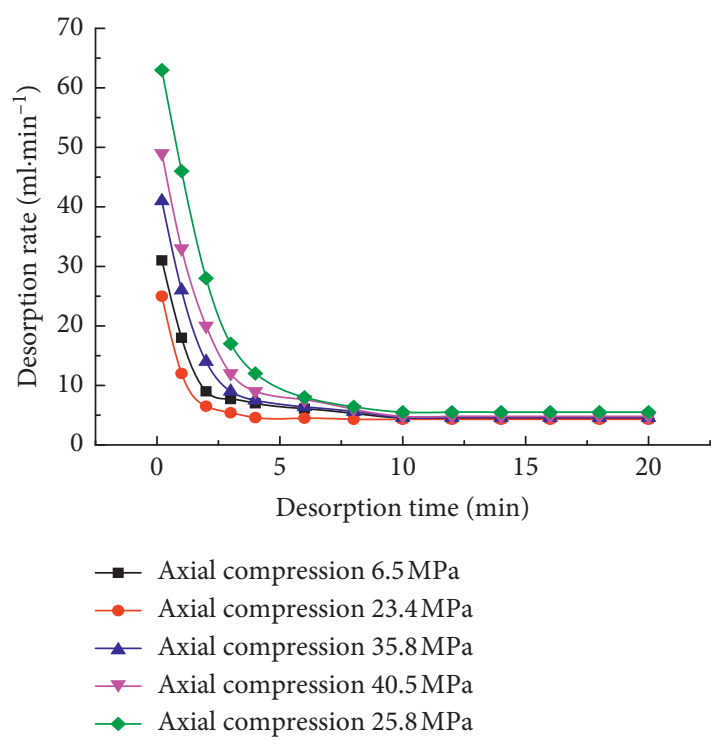

(c)

Figure 13: Desorption rate curve under the confining pressure of $3 \mathrm{MPa}$ at the temperature of (a) $30^{\circ} \mathrm{C}$, (b) $45^{\circ} \mathrm{C}$, and (c) $60^{\circ} \mathrm{C}$.

pore fractures that compressed during compaction and elastic deformation are reopened to form effective desorption surface area, and the new microcracks are produced. Fissured channel that is conducive to methane desorption is formed, the effective desorption surface area began to increase, the desorption and diffusion movement of methane is promoted, and the movement state of methane changes from inhibiting desorption to promoting desorption and diffusion in this process. Near the peak, with the increase in axial pressure, more new cracks appeared in the raw coal specimen and were interlinked, which formed a relatively developed fracture network, and the effective desorption surface area was further increased. In the residual deformation stage, the raw coal specimen is destroyed, the fracture network in the specimen is more developed, and the methane desorption channel and the effective desorption surface area expand rapidly, which greatly promotes desorption and diffusion of methane.

At the same confining pressure, the maximum desorption rate corresponding to the same deformation stage increases with the rising of temperature; this is mainly because the free methane molecular collision is intensified with the rise of temperature, which provides the energy for methane desorption. So, the adsorption between methane and coal surface molecules is weakened at the same time, which promoted the desorption and diffusion movement of methane. At the same temperature, the increase in confining pressure inhibited the development and expansion of pore fractures in the raw coal specimen and hindered the increase in the effective desorption surface area so that the maximum desorption rate corresponding to the same deformation stage decreased with the increase in confining pressure. 


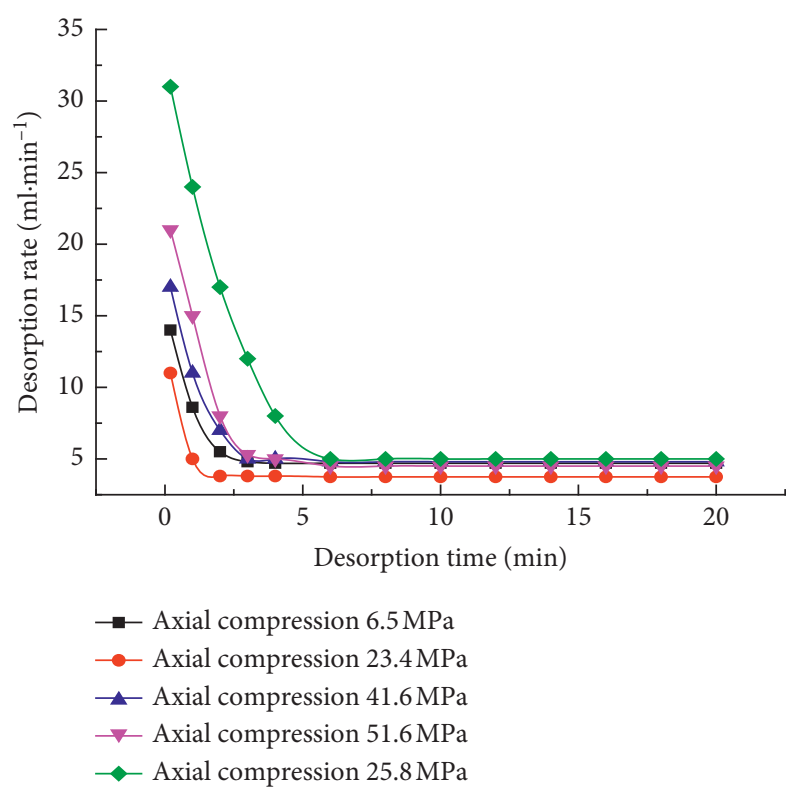

(a)

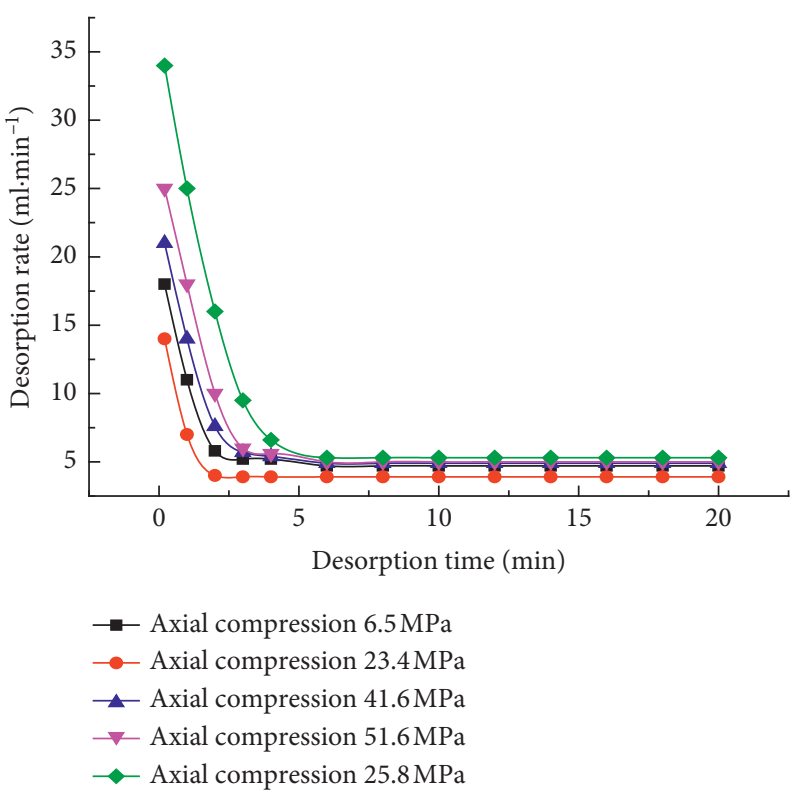

(b)

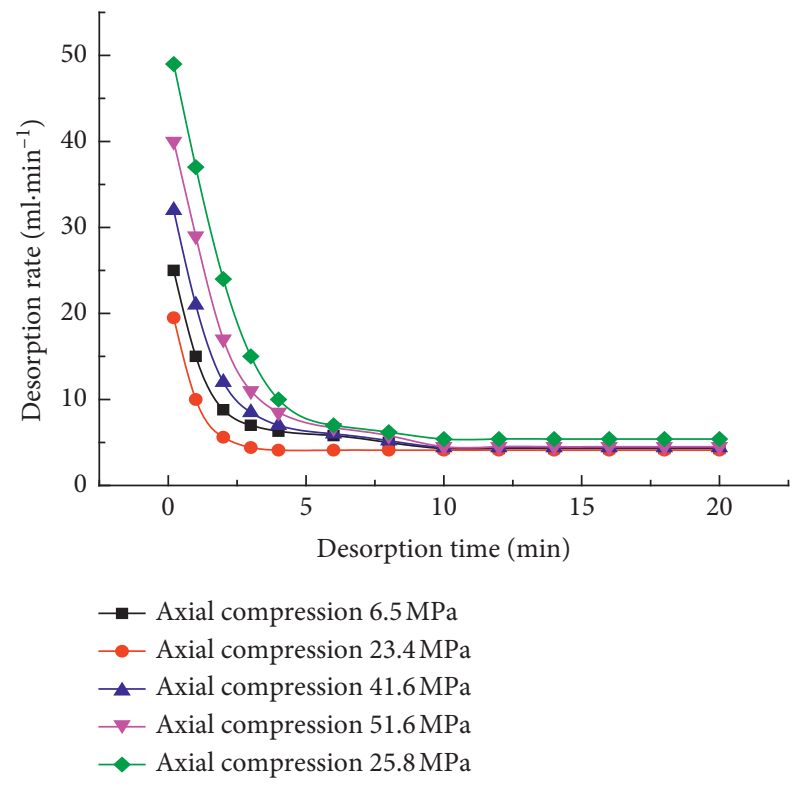

(c)

Figure 14: Desorption rate curve under the confining pressure of $5 \mathrm{MPa}$ at the temperature of (a) $30^{\circ} \mathrm{C}$, (b) $45^{\circ} \mathrm{C}$, and (c) $60^{\circ} \mathrm{C}$.

4.7. Discussion. Under the same temperature and methane pressure, the cumulative desorption amount of the specimen before the stress peak was less than that without loading, but the cumulative desorption amount after the stress peak was greater than that without loading. The main reason was that the development and expansion of cracks in the specimen were inhibited due to the loading before the stress peak, and the effective desorption surface area changed very little, which was not conducive to the desorption of methane, thus inhibiting the increase in the desorption amount. The higher the confining pressure, the more unfavorable the increase in the effective desorption surface area and desorption amount. The specimen was damaged after the stress peak, and the effective desorption surface area was obviously increased, which was conducive to the desorption of methane, and the desorption amount increased significantly. 


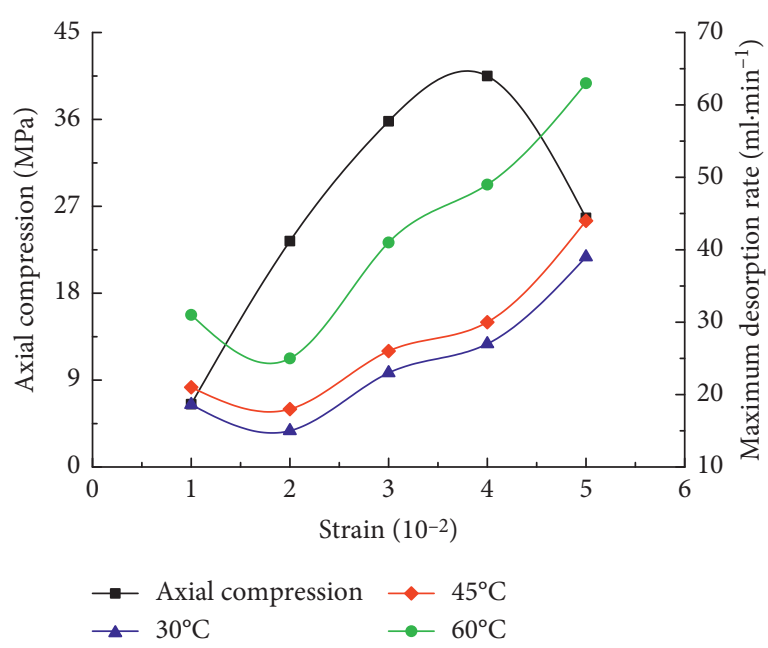

(a)

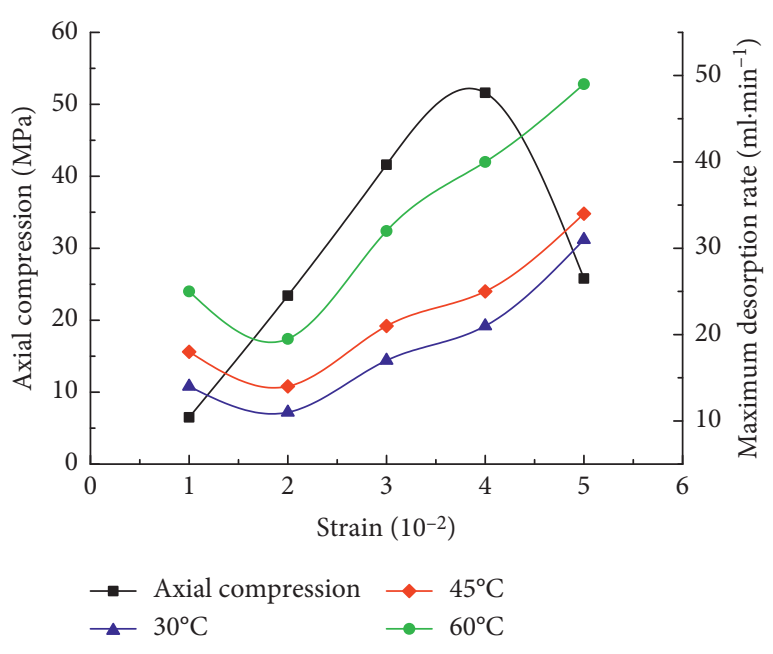

(b)

FIgURE 15: Relation curve between stress-strain and desorption rate under the confining pressure of (a) $3 \mathrm{MPa}$ and (b) $5 \mathrm{MPa}$.

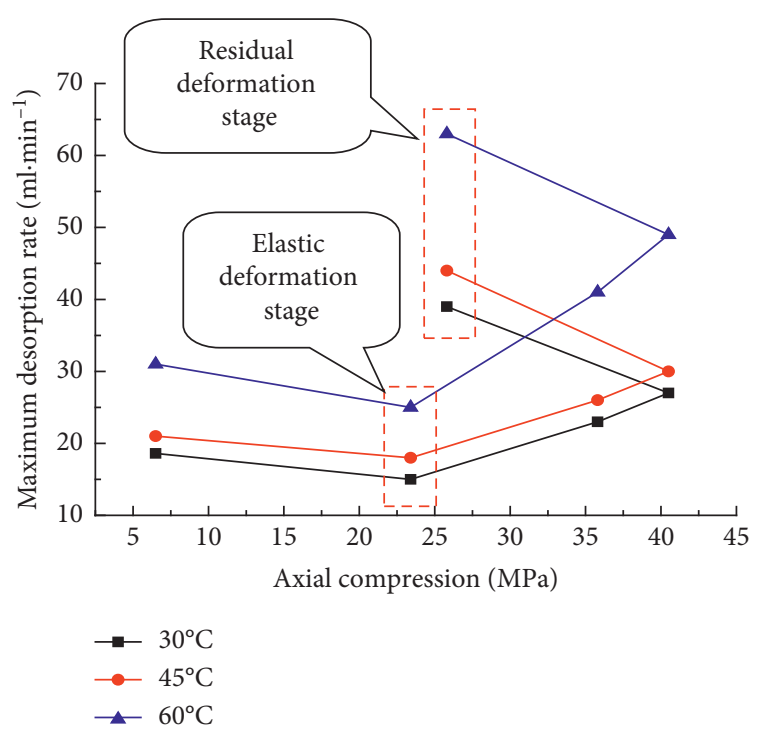

(a)

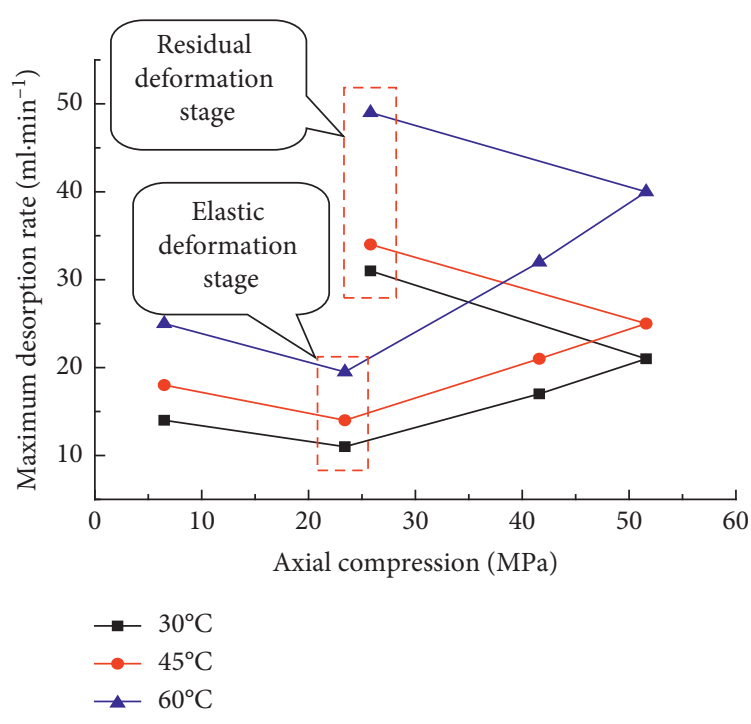

(b)

FIGURE 16: Relation curve between maximum desorption rate and axial pressure under the confining pressure of (a) $3 \mathrm{MPa}$ and (b) $5 \mathrm{MPa}$.

\section{Conclusion}

(1) The accumulated methane desorption amount of raw coal specimen at each deformation stage shows a convex parabolic increase trend with the increase in desorption time. Under the same desorption time, the cumulative desorption amount corresponding to different deformation stages from large to small is residual deformation stage, compaction stage, near the peak stress, plastic deformation stage, and elastic deformation stage.

(2) The methane desorption rate at different deformation stages shows a power function decay trend with the increase in desorption time. Under the same confining pressure, temperature, and methane pressure, the maximum desorption rate corresponding to different deformation stages from large to small is residual deformation stage, near the peak stress, plastic deformation stage, compaction stage, and elastic deformation stage.

(3) The influence law of temperature on the desorption characteristics is as follows. Under the condition of the same confining pressure and methane pressure, the thermal motion of methane molecules is intensified with the increase in temperature, the energy is provided for methane desorption, and the adsorption effect between methane molecules and the molecules at the surface of the coal is weakened at the 
same time. The desorption and diffusion of methane are promoted under the higher temperature, which presents the law of promoting desorption. The accumulated methane desorption amount and the maximum desorption rate of raw coal specimens at the same deformation stage increase with the increase in temperature and reach the maximum desorption amount at the residual deformation stage, and the methane desorption amount at this stage is obviously greater than that at other deformation stages.

(4) The influence law of confining pressure on the desorption characteristics is as follows. Under the condition of the same temperature and methane pressure, the development and expansion of pore fractures in raw coal specimen are inhibited and the increase in the effective desorption surface area is hindered with the increase in confining pressure, and the cumulative methane desorption amount and the maximum desorption rate at the same deformation stage is decreased with the increase in confining pressure.

\section{Data Availability}

The data used to support the findings of this study are included within the article.

\section{Conflicts of Interest}

The authors declare that they have no conflicts of interest.

\section{Acknowledgments}

This paper was financially supported by the National Natural Science Foundation (51904010, 51774009, 51874002, and 51874006), Natural Science Research Project of Colleges and Universities in Anhui Province (KJ2017A093), Anhui Provincial Natural Science Foundation (1808085QE149, 1808085ME159, and 2008085ME142), and Open Foundation From Key Laboratory of Safety and High-efficiency Coal Mining, Ministry of Education (JYBSYS2017105 and JYBSYS2018202).

\section{References}

[1] J. Liu, Z. Chen, D. Elsworth, X. Miao, and X. Mao, "Evolution of coal permeability from stress-controlled to displacementcontrolled swelling conditions," Fuel, vol. 90, no. 10, pp. 2987-2997, 2011.

[2] C. Ö. Karacan and G. D. Mitchell, "Behavior and effect of different coal microlithotypes during gas transport for carbon dioxide sequestration into coal seams," International Journal of Coal Geology, vol. 53, no. 4, pp. 201-217, 2003.

[3] M. Wang and D. Zhang, "Influences of moisture on adsorption and desorption of methane on gas shales," Energy Sources, Part A: Recovery, Utilization, and Environmental Effects, vol. 42, no. 11, pp. 1-9, 2020.

[4] L. Li, C. Li, and T. Kang, "Adsorption/desorption behavior of $\mathrm{CH}_{4}$ on shale during the $\mathrm{CO}_{2}$ huff-and-puff process," Energy \& Fuels, vol. 33, no. 6, pp. 5147-5152, 2019.
[5] G. Hu, Y. Zhu, and Z. Li, "Experimental study on desorption enhancing of methane in coal mass using a controlled microwave field," Chinese Journal of Rock Mechanics and Engineering, vol. 36, no. 4, pp. 874-880, 2017.

[6] T. Gao, D. Zhao, C. Wang, and Z. Feng, "Energy variation in coal samples with different particle sizes in the process of adsorption and desorption," Journal of Petroleum Science and Engineering, vol. 188, Article ID 106932, 2020.

[7] J. Li, Y. Wang, Z. Chen, and S. S. Rahman, "Simulation of adsorption-desorption behavior in coal seam gas reservoirs at the molecular level: a comprehensive review," Energy \& Fuels, vol. 34, no. 3, pp. 2619-2642, 2020.

[8] M. Wieckowski, N. Howaniec, and A. Smolinski, "Natural desorption of carbon monoxide during the crushing of coal simulating natural rock mass pressure," Science of the Total Environment, vol. 736, Article ID 139639, 2020.

[9] K. Czerw, P. Baran, J. Szczurowski, and K. Zarębska, "Sorption and desorption of $\mathrm{CO}_{2}$ and $\mathrm{CH}_{4}$ in vitrinite-and inertinite-rich polish low-rank coal," Natural Resources Research, vol. 29, no. 3, p. 09715, 2020.

[10] K. Lin, X. Huang, and Y.-P. Zhao, "Combining image recognition and simulation to reproduce the adsorption/desorption behaviors of shale gas," Energy \& Fuels, vol. 34, no. 1, pp. 258-269, 2020.

[11] X. Li, Z. Li, T. Ren et al., "Effects of particle size and adsorption pressure on methane gas desorption and diffusion in coal," Arabian Journal of Geosciences, vol. 12, no. 24, p. 794, 2019.

[12] C. Li, H. Xue, and W. Liu, "Experimental study on gas diffusion in coal under stress," Journal of China Coal Society, vol. 43, no. 3, pp. 717-723, 2018.

[13] P. Li, D. Ma, J. Zhang, and Z. Huo, "Wettability modification and its influence on methane adsorption/desorption: a case study in the ordos basin, China," Energy Science of Engineering, vol. 8, no. 3, pp. 804-816, 2020.

[14] F. Wang, Y. Luo, Y. Liang, J. Peng, and B. Li, "Sampling methane-bearing coal seams by freezing method: coalbed methane desorption and inhibition characteristics under freezing temperature," Natural Resources Research, vol. 29, no. 2, pp. 1351-1360, 2020.

[15] F. Quan, C. Wei, J. Zhang et al., "Study on desorption and diffusion dynamics of coal reservoir through step-by-step depressurization simulation--an experimental simulation study based on LF-NMR technology," Journal of Natural Gas Science and Engineering, vol. 75, Article ID 103149, 2020.

[16] K. Wang, J. Zang, Y. Feng, and Y. Wu, "Effects of moisture on diffusion kinetics in Chinese coals during methane desorption," Journal of Natural Gas Science and Engineering, vol. 21, no. 2, pp. 1005-1014, 2014.

[17] Z. Liu, Z. Feng, Q. Zhang, D. Zhao, and H. Guo, "Heat and deformation effects of coal during adsorption and desorption of carbon dioxide," Journal of Natural Gas Science and Engineering, vol. 25, pp. 242-252, 2015.

[18] D. Zhou, Z.-C. Feng, D. Zhao, Y.-S. Zhao, and T.-T. Cai, "Experimental study of meso-structural deformation of coal during methane adsorption-desorption cycles," Journal of Natural Gas Science and Engineering, vol. 42, pp. 243-251, 2017.

[19] K. Zhang, Y. Cheng, L. Wang, J. Dong, C. Hao, and J. Jiang, "Pore morphology characterization and its effect on methane desorption in water-containing coal: an exploratory study on the mechanism of gas migration in water-injected coal seam," Journal of Natural Gas Science and Engineering, vol. 75, Article ID 103152, 2020. 
[20] Y. Ma, N. Zhong, L. Yao, H. Huang, S. Larter, and W. Jiao, "Shale gas desorption behavior and carbon isotopic variations of gases from canister desorption of two sets of gas shales in south China," Marine and Petroleum Geology, vol. 113, Article ID 104127, 2020.

[21] G. Yue, C. Zeng, L. Huo, and X. Zheng, "Measurement and modeling of temperature evolution during methane desorption in coal," Scientific Reports, vol. 10, no. 1, Article ID 3146, 2020.

[22] Q. Xu, S. Yang, Z. Tang et al., "Optimum oxidation temperature of coal bed for methane desorption in the process of CBM extraction," Fuel, vol. 262, Article ID 116625, 2020.

[23] J. Meng, S. Li, J. Niu et al., "Effects of moisture on methane desorption characteristics of the zhaozhuang coal: experiment and molecular simulation," Environmental Earth Sciences, vol. 79, no. 1, p. 44, 2020.

[24] Z. Wang, X. Wang, X. Ma, X. Li, and Z. Zhu, "Laboratory measurements of methane desorption behavior on coal under different modes of real-time microwave loading," Adsorption, vol. 26, no. 1, pp. 61-73, 2020.

[25] L. Li, Z. Sun, F. Wang, and K. Zhang, "Study on the gas desorption law and indicator influencing factors of fixed-size coal samples," Scientific Reports, vol. 9, Article ID 17134, 2019.

[26] X. Bai, C. Wu, X. Liu, and Y. Li, "Analysis of the tempo-spatial effects of hydraulic fracturing by drilling through underground coal mine strata on desorption characteristics," Energy Science \& Engineering, vol. 7, no. 1, pp. 170-178, 2019.

[27] Z. Dong, C. Zhang, H. Chen, and Z. Feng, "Experimental study on gas desorption characteristics for different coal particle sizes and adsorption pressures under the action of pressured water and superheated steam," Journal of Petroleum Science and Engineering, vol. 179, pp. 948-957, 2019.

[28] G. Wang, T. Ren, K. Wang, and Y. Wu, "Influence of maximum pressure on the path of $\mathrm{CO}_{2}$ desorption isotherm on coal," Energy \& Fuels, vol. 28, no. 11, pp. 7093-7096, 2014.

[29] S. Kong, X. Huang, K. Li, and X. Song, "Adsorption/desorption isotherms of $\mathrm{CH}_{4}$ and $\mathrm{C}_{2} \mathrm{H}_{6}$ on typical shale samples," Fuel, vol. 255, Article ID 115632, 2019.

[30] C. Li, Y. Nie, and Y. Ma, "Effects of particle mixing on characteristics of gas desorption and non-constant dynamic diffusion in coal," Energy Sources, Part A: Recovery, Utilization, and Environmental Effects, vol. 1, Article ID 1678699, 2019.

[31] N. Skoczylas, A. Pajdak, and M. Młynarczuk, " $\mathrm{CO}_{2}$ adsorption-desorption kinetics from the plane sheet of hard coal and associated shrinkage of the material," Energies, vol. 12, no. 20, p. 4013, 2019.

[32] J. Yu, W. Yao, K. Duan, X. Liu, and Y. Zhu, "Experimental study and discrete element method modeling of compression and permeability behaviors of weakly anisotropic sandstones," International Journal of Rock Mechanics and Mining Sciences, vol. 134, Article ID 104437, 2020.

[33] M. Duan, C. Jiang, Q. Gan, M. Li, K. Peng, and W. Zhang, "Experimental investigation on the permeability, acoustic emission and energy dissipation of coal under tiered cyclic unloading," Journal of Natural Gas Science and Engineering, vol. 73, Article ID 103054, 2020.

[34] W. Shi, X. Wang, C. Zhang, A. Feng, and Z. Huang, "Experimental study on gas content of adsorption and desorption in fuling shale gas field," Journal of Petroleum Science and Engineering, vol. 180, pp. 1069-1076, 2019.

[35] W. Lu, B. Huang, and X. Zhao, "A review of recent research and development of the effect of hydraulic fracturing on gas adsorption and desorption in coal seams," Adsorption Science \& Technology, vol. 37, no. 5-6, pp. 509-529, 2019. 